Portland State University

PDXScholar

\title{
The Determination of Normal Bone Conducted Speech Results Utilizing a Radioear B-72 Bone Oscillator
}

Roger Edwin Lundberg

Portland State University

Follow this and additional works at: https://pdxscholar.library.pdx.edu/open_access_etds

Part of the Speech and Hearing Science Commons

Let us know how access to this document benefits you.

\section{Recommended Citation}

Lundberg, Roger Edwin, "The Determination of Normal Bone Conducted Speech Results Utilizing a Radioear B-72 Bone Oscillator" (1981). Dissertations and Theses. Paper 3067.

https://doi.org/10.15760/etd.3061

This Thesis is brought to you for free and open access. It has been accepted for inclusion in Dissertations and Theses by an authorized administrator of PDXScholar. Please contact us if we can make this document more accessible: pdxscholar@pdx.edu. 
AN ABSTRACT OF THE THESIS OF Roger Edwin Lundberg for the Master of Science in Speech Communication presented June 5, 1981 .

Title: The Determination of Normal Bone Conducted Speech Results Utilizing a Radioear B-72 Bone Oscillator.

APPROVED BY MEMBERS OF THE THESIS COMMITTEK

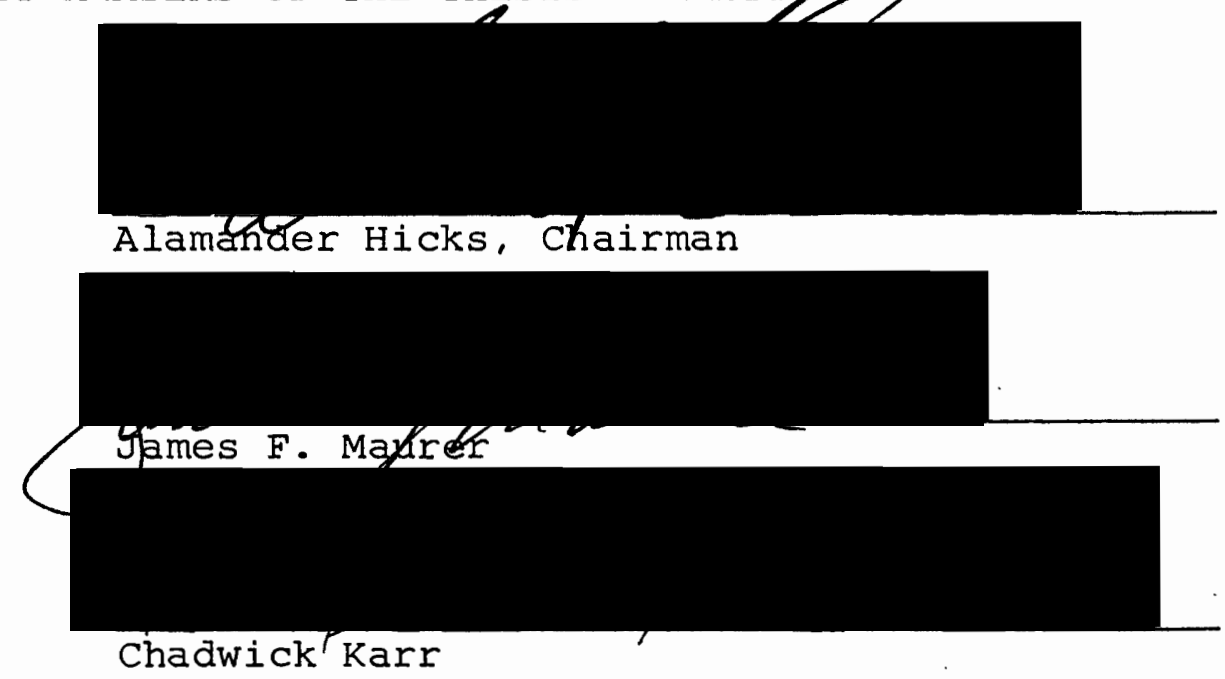

The purpose of this study was to establish a normal, bone conducted intensity level for the speech reception threshold (SRT) and obtain a normal performance intensity function by bone conduction from $0 \mathrm{~dB}$ SL (threshold) through the maximum output level of the standard audiometer. All bone conducted speech test materials consisted of prerecorded $\mathrm{W}-2$ spondiac words and NU-6 monosyllabic speech discrimination word lists. 
Twenty-six normal hearing subjects gave written responses to tape recorded word lists presented through a Radioear B-72 bone oscillator. Since the experimental conditions were limited to only the better ear, the non-test ear was isolated utilizing speech masking noise.

The mean SRT was found to be $47.5 \mathrm{~dB} \mathrm{HL}$ and speech discrimination testing conducted at $25 \mathrm{~dB}$ SL and above demonstrated high reliability. However, bone conducted speech discrimination results from $0 \mathrm{~dB}$ SL through 20 dB SL revealed wide variances and were not recommended for clinical testing. Further, it should be noted that these speech discrimination tests may be administered at the limits (95-100 $\mathrm{dB} \mathrm{HL}$ ) of the standard audiometer without deleteriously affecting speech discrimination performance. 
THE DETERMINATION OF NORMAL BONE CONDUCTED SPEECH RESULTS UTILIZING A RADIOEAR B-72 BONE OSCILLATOR

by

ROGER EDWIN LUNDBERG

A thesis submitted in partial fulfillment of the requirements for the degree of

MASTER OF SCIENCE

SPEECH

with emphasis in Speech Pathology

and Audiology

Portland State University

1981 
TO THE OFFICE OF GRADUATE STUDIES AND RESEARCH:

The members of the Committee approve the thesis of Roger Edwin Lundberg presented June 5, 1981.

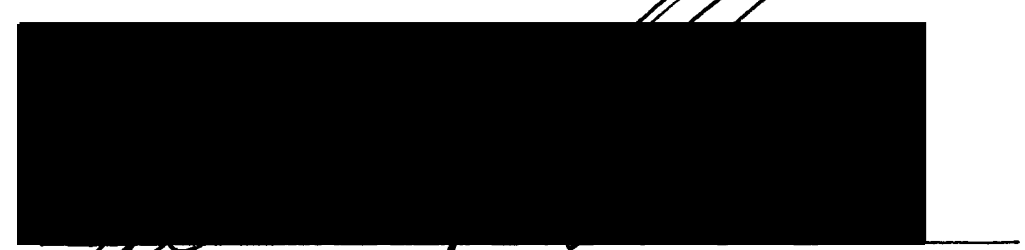

AlCmander Hicks,/Chairman

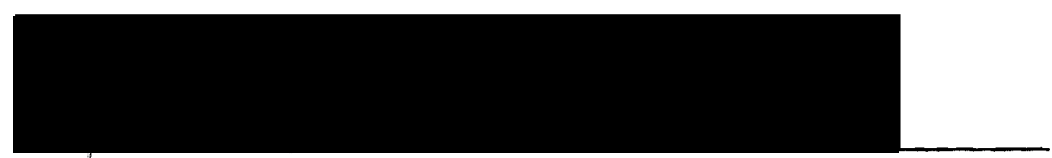

James F. Maurer

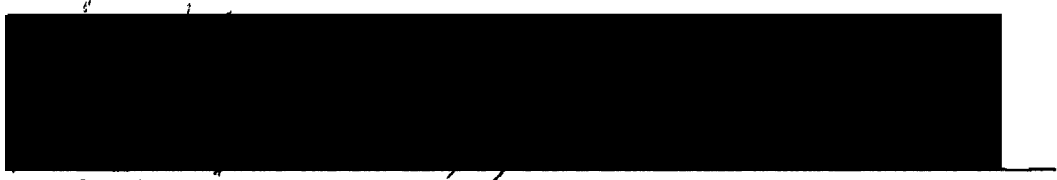

Chadwick Karr

\section{APPROVED:}

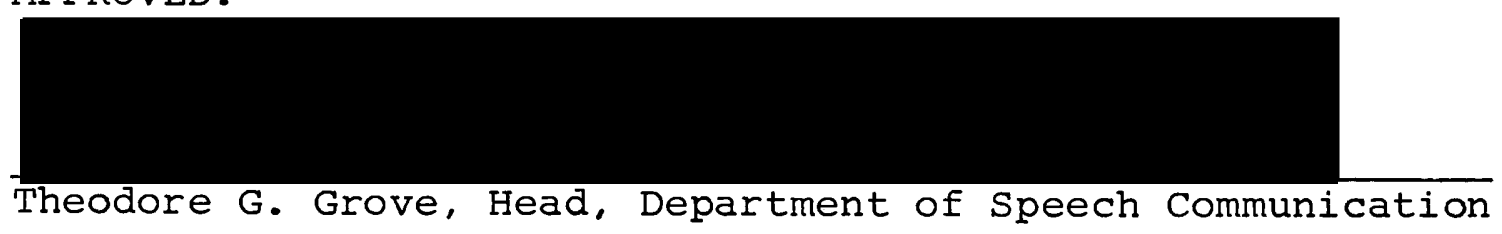

Stanley E. Rauch, Dean of Graduate Studies and Research 


\section{ACKNOWLEDGEMENTS}

This project would never have gotten started nor completed if it had not been for the many people who gave of their time, knowledge and support. It is my privilege to single out a few of these individuals to whom I owe so much.

At no small expense to himself, Dr. Al Hicks who served as my academic advisor and thesis committee chairman gave graciously of his time and knowledge. His perceptive and encouraging nature more than once kept this author from throwing in the towel.

A special debt of gratitude is felt for Dr. James Maurer who not only sold me on the profession of audiology but provided continued support throughout my graduate coursework and thesis research.

I would like to sincerely thank Dr. Chad Karr for his openness, and marvelous willingness to emmerse himself into a rather arcane area of audiology.

I am indebted to Terry Cochrane, a fellow audiology student who encouraged me to explore bone conducted speech testing.

I also am very appreciative of those 26 speech and hearing students who freely and without complaint participated in two hours of rigorous testing. 
A special thanks is also given to the many typists who contributed to this research. In particular, Leslie Fitzpatrick's and Stewart Martin's efforts to have this thesis printed by computerized typing was greatly appreciated.

Finally, to Michaela one of the sweetest little kids whoever let her daddy work on his "report," thank you. And, to Jacqueline whose strength and understanding gave me the perserverance to finish, I owe you more than I can express. 
In dedication and love to Roger Sr., Molly, Jacqueline and Michaela 
TABLE OF CONTENTS

PAGE

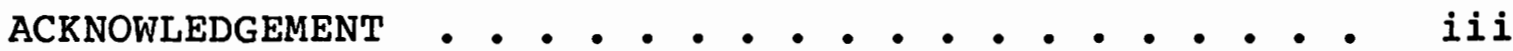

DEDICATION . . . . . . . . . . . . . . . . v v v v

LIST OF TABLES . . . . . . . . . . . . . . . viii

LIST OF FIGURES . . . . . . . . . . . . . . ix

CHAPTER

I INTRODUCTION •. . . . . . . . . . . 1

II REVIEW OF LITERATURE . . . . . . . . . . 3

PURE TONE BONE CONDUCTION MEASUREMENTS . • . 4

Calibration of Bone Conduction Apparatus 17

SPEECH BY BONE CONDUCTION . . . . . . 30 PURPOSE . . . . . . . . . . . . . 47 47

Rationale ........... 47

II METHODS . . . . . . . . . . . 49

Subjects .............. 48

Procedure ............. 50

Instrumentation .......... 51

Calibration . . . . . . . . 52

IV RESULTS . . . . . . . . . . . . 54 
vii

V DISCUSSION AND SUMMARY ........... 63

Conclusion ... . . . . . . . 71

Implication for Further Research . . 72

REFERENCES . . . . . . . . . . . . . . . . 74 


\section{LIST OF TABLES}

I Results of the bone conduction data accumulated at the University of California and the Veterans Administration Hospital in Los Angeles, California . . . . . . . . 27

II Portland State University standard calibration data . . . . . . . . . . . . 55

II Mean bone conduction calibration values determined by the experimental population . 55

IV The average pure tone threshold and speech reception threshold for both air and bone conduction . . . . . . . . . . . 58

$\mathrm{V}$ The mean word discrimination scores as a function of increased intensity . . . . . 59

VI The mean percentage scores for both bone and air conduction studies .. . . . . 67 
1. Early audiometer equipped with air and bone conduction, the "Audio-Amplifier." . . . . . 6

2a. Hearing aid-type bone conduction vibrator . . . 8 2b. Schematic drawing of hearing aid-type bone conduction vibrator . . . . . . . . . 8

3a. Schematic drawing of the Western Electric bone conduction vibrator, Model 700A . . . . 10

3b. Simplified sketch of the magnetic components of the Western Electric 700A . . . . . . 10

4. Western Electric 700A with lorgnette type handie 11

5. Radioear B-70A, B-7I, and B-72 bone vibrators - 15

6. Schematic drawing of the first artificial mastoid, including operating parts . . . . . . 20

7. Schematic view of strain-gauge type artificial mastoid . . . . . . . . . . 22

8. A view from the top of the Beltone Artificial mastoid, illustrating the position of the bone vibrator

9. Cutaway view of the Bruel and Kjaer artificial mastoid . . . . . . . . . . . 28 
11. The Hearing Fan . . . . . . . . . . 33

12. Watson and his bone conduction vibrator ... 35

13. The articulation function of one subject by bone conduction and a comparison of performance by air conduction . . . . . . . . . 36

14. The pure tone audiogram reveals an air bone gap and speech audiometry by air and bone conduction confirms the presense of a conductive component. Assessment - mixed loss of hearing . . . . 40

15. An identical pure tone audiogram as seen in

Figure 14 is shown to be invalid due to the overlap of speech discrimination scores by air and bone conduction. Assessment sensorineural hearing loss . . . . . . 41 16. Oticon A20 bone vibrator . . . . . . . . 44

17. Articulation gain function for bone conducted speech using a Radioear B-70A vibrator . . 46 18. The mean discrimination scores by bone conduction . . . . . . . . . . . .

19. A comparison between air and bone conducted speech discrimination scores as a function of sensation level (SL) . . . . . . . . . 68

20. A comparison between air and bone conducted speech discrimination scores as a function of sound pressure level (SPL) . . . . . . . 70 


\section{CHAPTER I}

\section{INTRODUCTION}

Bone conduction refers to the response of bones of the skull to audiofrequency vibrations, and to the transmission of such vibrations to, and the reception by the sensory hair cells of the cochlea. Skull vibrations may arise because the head is in a sufficiently intense sound field, or because the skull is in direct contact with a vibrating object (Tonndorf, 1972).

Hood (1962) suggested that the bone conduction system in man had no specific useful purpose. Dirks (1978) observed that the principal interest in bone conduction measurements has been its usefulness as a diagnostic tool when determining the presence or absence of a middle ear or conductive hearing loss.

In the early years, the notion was widely held that bone conduction might bypass cochlear reception and stimulate the auditory nerves directly (Pohlman and Kranz, 1926). Bekesy (1932) demonstrated experimentally that a bone conducted tone could be cancelled out by an air conducted tone of the same frequency when it was delivered $180^{\circ}$ out of phase. This indicated that air and bone conducted signals cause similar movements of the endolymphatic fluid and of 
the basilar membrane. From this evidence Bekesy concluded that an osseous rather than an osseotympanic pathway was the prominent route for the transmission of bone conducted sound (Senturia and Thea, 1942). Lowy (1942) utilizing cochlear microphonics repeated Bekesy's experiments and proved that phase cancellation can occur only within the cochlea: Lowy further observed that once cancellation is achieved for a given electrode position along the cochlea, the entire cochlear partition comes to rest momentarily.

Tonndorf (1972) suggested that the findings of Bekesy and Lowy were consistent with current auditory theory. In particular, these researchers demonstrated that bone and air conducted signals generate similar if not identical displacements of the basilar membrane by the formation of traveling waves. 
CHAPTER II

\section{REVIEW OF LITERATURE}

pure tone bone conducted measurements which originated during the early part of the 19 th century have been an integral part of otology and modern audiology (Tonndorf, 1972). Dirks (1978) observed that bone conduction measurements next to air conduction measurements have been the most frequently used procedure in clinical audiology. Notwithstanding this importance within the test battery, Dirks emphasized that bone conduction measurement is plagued with numerous inherent problems. This paper will address some of these difficulties, but predominantly the following discussion will focus on the calibration and standardization of bone apparatus.

It should be noted here that speech audiometry by bone conduction was developed as a partial remedy to some of the disadvantages of pure tone bone conduction measurements (Pohlman, 1929). Although many researchers have lamented the fact that this procedure has not gained wide acceptance and use in the field of audiology (Robinson and Kasden, 1970; Merrell et al., 1973; and stockdell, 1974)., bone conducted speech measurements have several distinct advantages which will become clear in the following discussion. 
PURE TONE BONE CONDUCTION MEASUREMENTS

Tonndorf (1972) reviewed the history of bone conduction and credited both wheatstone in England and Tourtual in Germany with the first reports on the clinical use of bone conduction tests as early as 1827. These early measurements were obtained utilizing a tuning fork, and it was not until the beginning of the 20 th century that the first bone conduction vibrator was powered by an audiometer (Pohlman and Kranz, 1923). These authors claimed their equipment met the following requirements:

1. Must be possible to deliver the energy to the bone in a series of graded intensities.

2. Must maintain a given pitch and intensity for an indefinite period of time.

3. Any given intensity must be accurately reproducible.

4. Must be easily transported, standardized and practically fool-proof.

Although requirements one through three may have been technologically possible in 1923, number four remains today a highly disputed claim. Accurate standardization of bone conduction apparatus has not been achieved (Wilbur, 1978), and the claim of their equipment being "practically fool-proof" seems to underscore these early researchers' tendency for hyperbole.

Two years later, Pohlman and Kranz (1925) described their bone conduction receiver as a modified telephone receiver activated by alternating electrical currents from 
a vacuum tube electric oscillator. This arrangement allowed tones of any desired frequency to be produced. The usual diaphragm of the telephone receiver was removed and a heavy strip of iron was used in its place. A projecting rod, with a flat plate which could be applied to the head, was then attached to the iron strip. In this way, a considerable force of comparatively small amplitude was provided. This permitted pressure from the plate against the head without disturbing the adjustment or relation of the bar to the magnets. The intensity was varied or attenuated in known increments utilizing a series of electrical resistances. This grenade-shaped vibrator was capable of delivering five frequencies (from 256-3300 $\mathrm{Hz}$ ) each covering slightly less than one octave (Pohlman and Kranz, 1925).

Knudsen and Jones (1924) developed a similar audiometer with four important features. This early apparatus which they called an "Audio-Amplifier" included: a speech amplifier, an audiometer for pure tones, a special receiver for measuring bone conduction, and a noise apparatus (see Figure 1). The bone conduction receiver was also grenade-shaped and bore a remarkable resemblance to the bone conduction receiver used by Pohlman and Kranz (1923).

Jones and Knudsen (1936) discussed the role of audiometry in prescribing hearing aids. Based upon their improved audio-amplifier and their recent research in the laboratories of the sonotone corporation, they introduced 


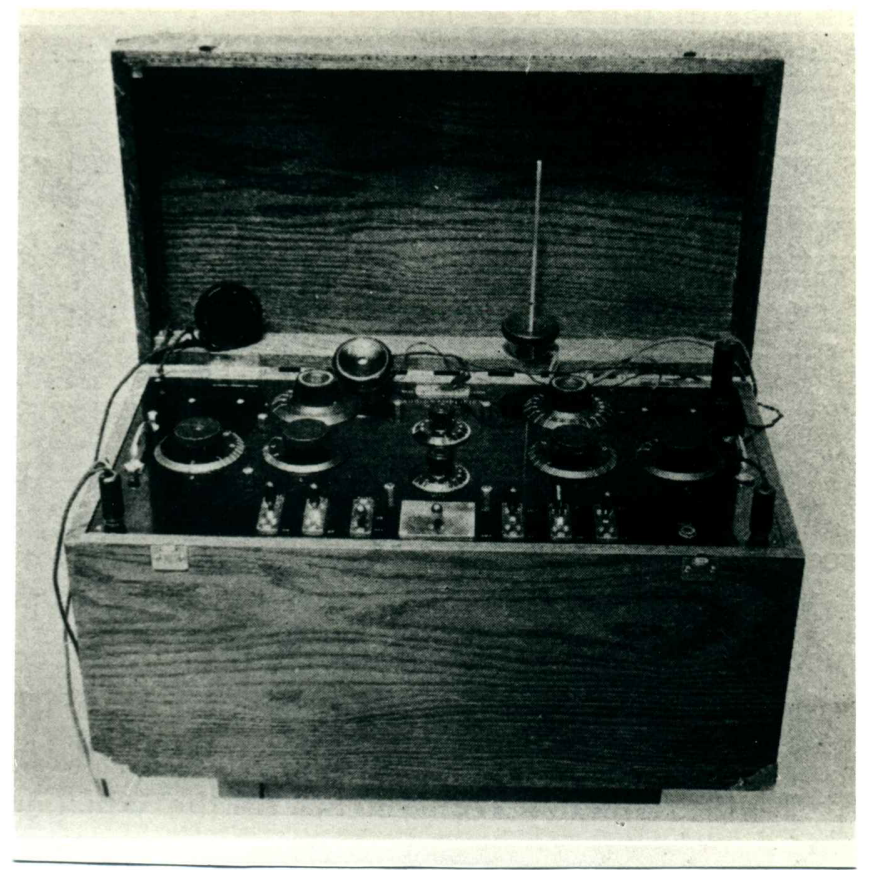

Figure 1. The Audio-Amplifier developed by Knudsen and Jones (1924). 
a new air conduction and bone conduction receiver. Their new bone conduction receiver which was similar to the transducer developed by Bekesy (1939) was shielded by a rubber flange which, "excluded hearings by aid conauction" (Jones and Knudsen, 1936). They believed that their bone conduction receiver was not influenced by the degree of pressure with which it was held against the head (see Figure $2 \mathrm{a}$ and $2 \mathrm{~b})$. Jones and Knudsen (1936) announced that an attractive feature of their bone conduction receiver was "its use for amplified conversational voice and whisper."

These researchers' apparent enthusiasm and confidence in bone conduction audiometry, however, was not shared by all the members of the otological society. The first formal symposium on bone conduction audiometry was conducted in 1936. In the report from The Committee on Methods of Testing Hearing by Bone Conduction it was noted that there was no assurance that any of the bone conduction receivers would hold calibration for a period of years. Secondly, bone conduction receivers of the same make and model might generate different amounts of acoustic energy for the same flow of current. And, thirdly, there was a lack of correlated information based on their use. The Committee on Methods of Testing by Bone Conduction summarized that bone conduction receivers did not surpass the reliable data gained from "good tests with tuning forks" (1936). Furthermore, The Committee postulated the belief that normal hearing individuals can 


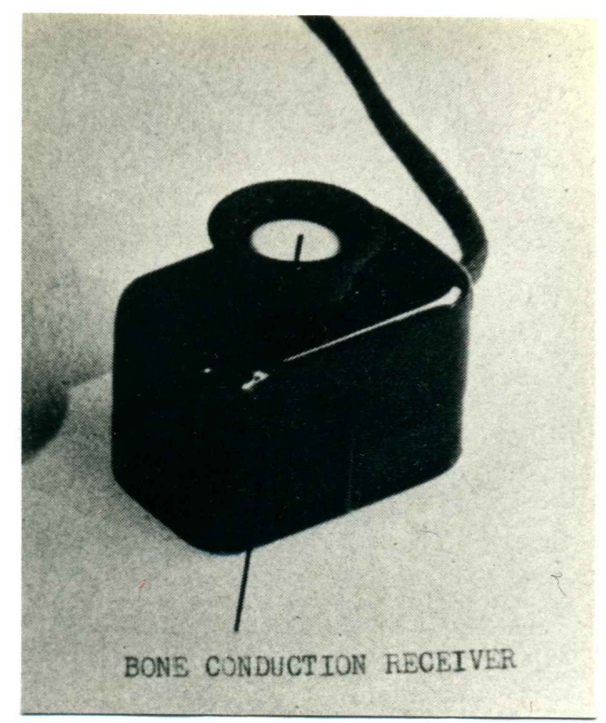

Eigure 2a. The hearing aid-type bone vibrator (Jones and Knudsen, 1936).

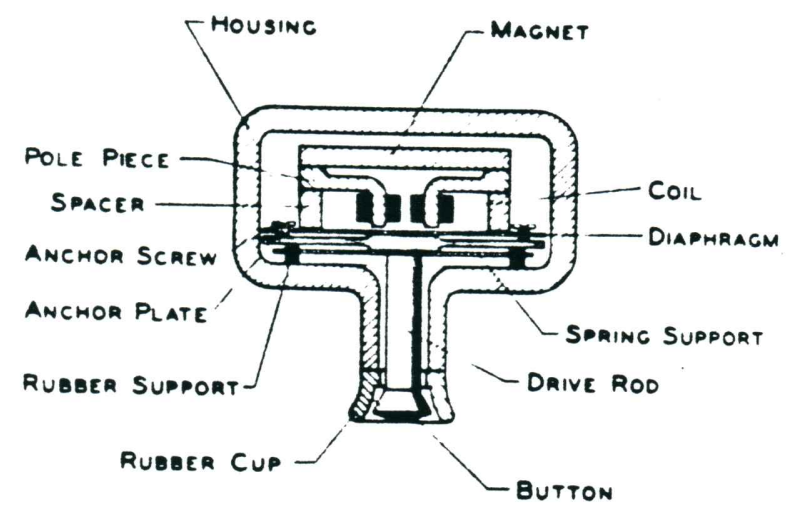

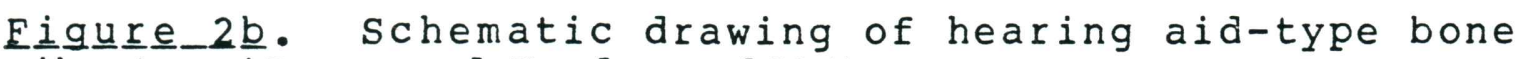
vibrator (Jones and Knudsen, 1936). 
hear by air conduction when the sound is at threshold intensity for bone conduction and that the use of lower frequencies for bone conduction tests was limited by the factor of tactile sensitivity.

A comparison between the two most common types of bone oscillators was conducted by Grossman and Molloy (1944). They compared the performance of a grenade-shaped oscillator which had a rod connected to an electromagnetically excited driving system to the performance of a hearing aid-type oscillator made by Western Electric, Model 700A.

The construction of the Western Electric $700 \mathrm{~A}$ bone conduction vibrator can be seen in Figure $3 a$ and $3 b$. The $700 \mathrm{~A}$ which was developed in 1935 by the Bell Laboratories was $13 / 8$ by $3 / 4$ inches and the front was slightly curved to conform to the shape of the mastoid bone. It was designed to be worn with a headband of light music wire, or as can be seen in Figure 4, hand held by a lorgnette type handle (Miner, 1935).

Grossman and Molloy (1944) concluded that the older bone vibrators were more accurate than the hearing aid-type. In particular, these investigators found a greater variability in the response of the hearing aid-type receiver than in the older grenade-type vibrators. Further, Grossman and Molloy reported that the amount of nonlinear distortion in the hearing aid bone vibrator was rather large at the low frequencies, i.e. below $500 \mathrm{~Hz}$. These investigators concluded 


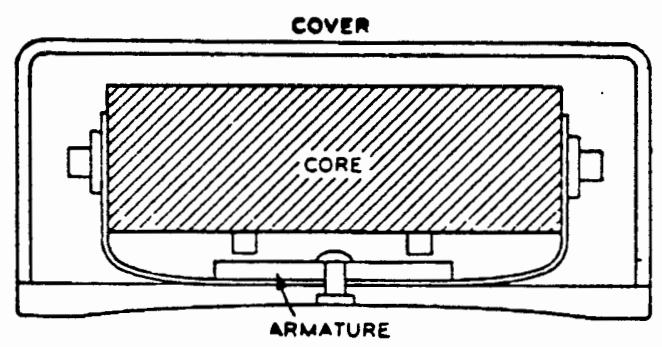

FIGURE 3a. Schematic drawing of the Western Electric bone vibrator, Model 700A (Miner, 1935).

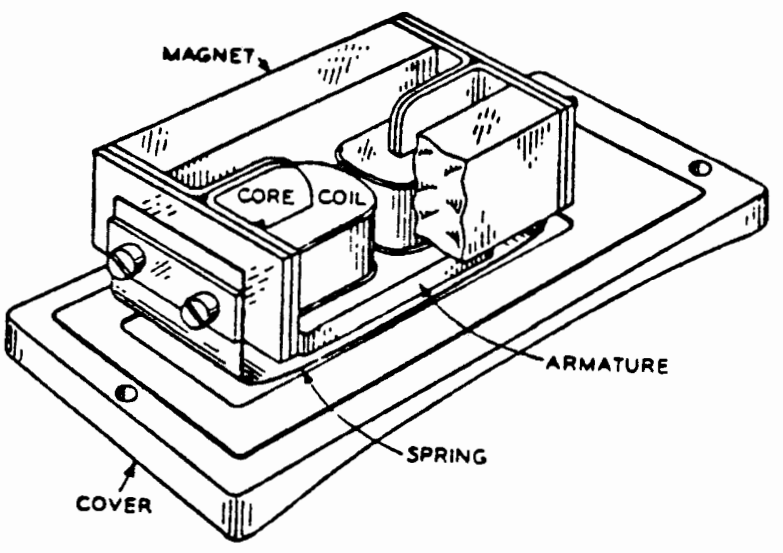

FIGURE 3b. Simplified sketch of the magnetic components of the WE 700A (Miner, 1935). 


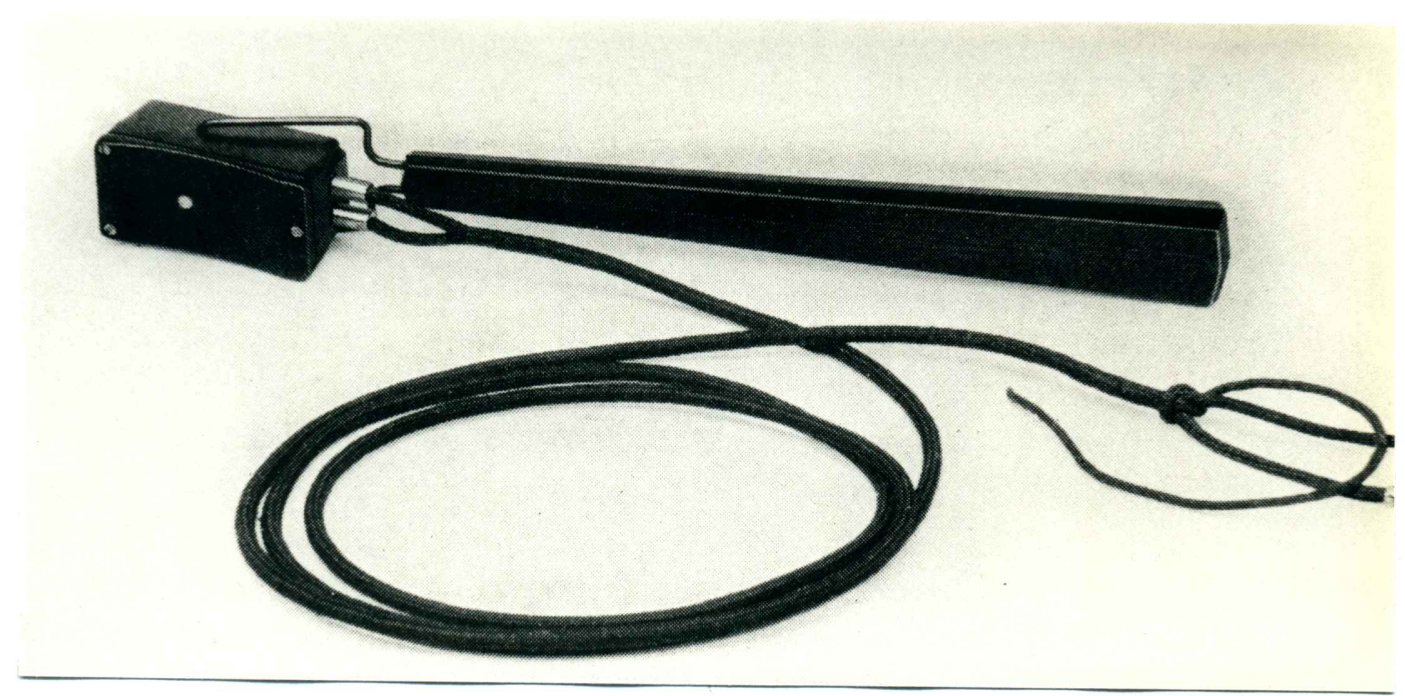

Figure 4. The Western Electric $700 \mathrm{~A}$ bone vibrator with lorgnette handle (Miner, 1935). 
that no definite value in any measure, decibel or otherwise, could be validated with current bone conduction receivers as an authentic measurement of hearing threshold. However, they suggested that the trend of the audiometric curve as well as its general position in the audiogram did permit the experienced otologist to utilize this information as a symptom of hearing impairment.

Lierle and Reger (1946) took issue with the Grossman and Molloy study on the grounds that the sonotone BR- 66 hearing aid-type bone vibrator (developed by Jones and Knudsen, 1936) was not prone to the same faults as the $700 \mathrm{~A}$ bone vibrator and therefore not subject to the same criticisms. Lierle and Reger suggested that properly constructed, calibrated, and used, bone conduction vibrators possessed sufficient reliability and accuracy to justify their continued use.

Sanders and Olsen (1964) and Wilbur and Goodhill (1967) also reported undesirable harmonic distortion at low frequencies for another hearing aid-type vibrator the Radioear B-70A. Wilbur and Goodhill compared three supposedly identical bone vibrators (Radioear B-70A) utilizing the Beltone 5A artificial mastoid and monitored the voltage which was fed to each vibrator across the vibrator terminals. At a constant. I volts, the distortion of a $250 \mathrm{~Hz}$ tone was found to be approximatley 42 percent for vibrator A, 25 percent for vibrator $B$, and 20 percent for vibrator $C$. 
Distortion for higher frequencies was found to be generally less than 10 percent. It was noted that, when these vibrators were used to measure theshold on a sample population, no systematic difference could be attributed to the magnitude of the harmonic distortion. These investigators did report that the standard deviations for the bone conduction measurements were larger than for the air conduction measurements, but they suggested this phenomenon was due to "subject variability" (Wilbur and Goodhill, 1967).

In 1967, studebaker compared three of the most commonly used bone conduction vibrators of that time. He stated that the $B-70 A$ was the most commonly used vibrator of the three and his research demonstrated that it was particularly sensitive to variation in application force. When the application force was varied from $500 \mathrm{gm}$ to $300 \mathrm{gm}$ at a mastoid placement, the output of the $B-70 \mathrm{~A}$ varied as much as nine decibels at 500 and $2000 \mathrm{~Hz}$. The Sonotone 9650 or B-9 bone vibrator faired better, varying no more than two decibels, across all test frequencies. The third hearing aid-type vibrator tested was the sonotone 6-AS and its performance, by comparison, was not as stable as the sonotone B-9 but better than the Radioear B-70A vibrator.

In 1972, The American standards Institute (ANSI s3.13-1972) issued impedance characteristics for an artificial mastoid. These artificial mastoid specifications 
were intended for use with bone vibrators that had a circular contact tip area of $1.75 \mathrm{~cm} 2$, and were to be applied to the skull with a static force of 5.4 Newtons (N) or approximately 550 grams weight. The Radioear Corporation (1973) developed two new bone vibrators, the Radioear B-7I and B-72 which incorporated the recommended circular contact tip area of $1.75 \mathrm{~cm}^{2}$. In addition, a headband assembly (Radioear P-3333) made of tempered spring steel, was also developed for the purpose of coupling these bone vibrators to an adult head with an average application force of $5.4 \mathrm{~N}$.

Figure 5 contains a photograph of the new bone vibrators (B-72 and B-7I) and, for comparison, the B-70A is also displayed. Note that the B-70A has a slightly concave area of contact and, by comparison, the B-72 and B-7I bone vibrators have a circular contact tip which is $1.7 \mathrm{~cm}$ in diameter with a corner radius of $0.1 \mathrm{~cm}$. Although the $\mathrm{B}-72$ is larger than the B-7l, they are both magnetic devices utilizing the mass reaction principle (Dirks and Kamm, 1975). The resonate peak of the $\mathrm{B}-72$ is $250 \mathrm{~Hz}$ which is much lower than found in either the B-71 $(\approx 500 \mathrm{~Hz})$ or $B-70 A(\approx 600 \mathrm{~Hz})$, (Radioear Corp. Eng. Bull, 1973).

Dirks and Kamm (1975) measured the harmonic distortion at the major test frequencies (with the exception of 4000 Hz) for each of three B-7I and three B-72 vibrators. The distortion for the $B-71$ was low $(<3.0 \%)$ at 500,1000 , and $2000 \mathrm{~Hz}$ but extremely high $(28.1 \%)$ at $250 \mathrm{~Hz}$. The B-72 was 


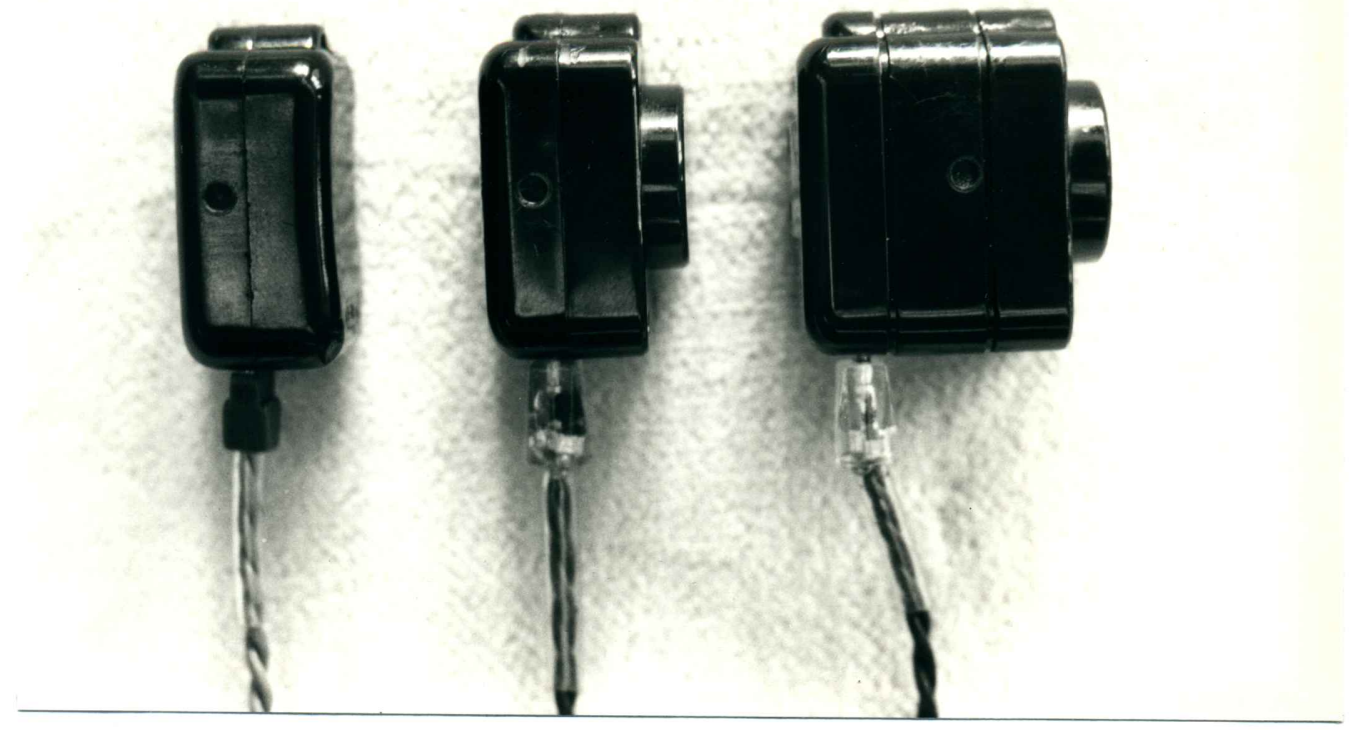

Figur 노도. The Radioear B-70A, B-71, and B-72 bone vibrators. 
comparable to the $B-71$ at all test frequencies except at $250 \mathrm{~Hz}$, the measured distortion was markedly reduced ( $(1.0 \%)$. Consequently, in terms of magnitude of harmonic distortion the $B-72$ bone vibrator appears to be superior to the $B-71$ vibrator.

Dirks (1978) lists calibration values for four different hearing aid-type vibrators. In addition to the three Radioear vibrators discussed, he also has values for the oticon $A-20$ bone vibrator. These four bone vibrators appear to represent most of the present bone vibrators used in clinical practice. The Radioear B-70A is clearly the most researched bone receiver, and appears to be the single most popular bone conduction receiver in use today (Audibel, 1980; Corvek, $1980)$.

In summary, the hearing aid-type vibrator is more convenient to use than the older grenade-shaped bone receiver and appears to be used exclusively by clinical audiologists. Further, with the development of the Radioear B-72 there is now a hearing aid-type vibrator with acceptable levels of harmonic distortion in the low frequencies. Although the B-70A may still be the most popular hearing aid-type vibrator, it does not meet current ANSI S3.13-1972 requirements of a $1.75 \mathrm{~cm}^{2}$ contact area. The $\mathrm{B}-72$, however, does meet this requirement and coupled with the Radioear head band ( $P-3333$ ) which generates the recommended application force of $550 \mathrm{gm}$, the Radioear $\mathrm{B}-72$ bone vibrator appears to 
be the most acceptable apparatus for current bone conduction measurements.

\section{Calibration of Bone Conduction Apparatus}

unfortunately, the apparatus and procedures required for the calibration of a bone vibrator present a more difficult task than those involved in the calibration of an earphone. While the microphone serves as a satisfactory transducer for the earphone it is entirely unacceptable for use with a bone vibrator. Most of the early attempts at bone conduction calibration were done by comparing the measurements obtained from air and bone conduction on normal hearing individuals (Pohlman and Kranz, 1926; Fowler and Fowler, 1936). These "normal" hearing individuals would be averaged and set down as the expected value for normal bone conduction thresholds. In this manner, the values obtained for "normal" bone conduction thresholds were relative to the particular audiometer used, and, therefore, could not be compared to the values obtained on a different audiometer.

Calibration procedures utilizing normal hearing human listeners later became known as the real ear technique for the calibration of bone vibrators (Carhart, 1950; AMA, 1951). However, since many audiometers did not deliver signals below audiometric zero, a true average "normal" threshold could not be determined. In an effort to resolve this problem, 
Roach and Carhart (1956) suggested using individuals with pure sensorineural losses for calibrating bone vibrators. This procedure had the advantage of eliminating ambient noise contamination while also increasing the possibility of obtaining valid thresholds. Unfortunately, the problem of screening out pure sensorineural losses who had no conductive component and whose loss did not extend beyond the bone conduction limits of the audiometer persisted.

Another basic problem with real ear calibration was demonstrated by Wilbur and Goodhill (1967). They demonstrated that among normal hearing subjects an individual subject can have thresholds in which air and bone conduction thresholds vary by as much as $15 \mathrm{~dB}$. Studebaker (1967) hypothesized an even larger disparity of $25 \mathrm{~dB}$ is possible according to a chance occurrence under the normal distribution theory.

Sanders and Olsen (1964) addressed the problem of obtaining valid measures for hearing sensitivity by bone conduction. They suggested that the uncertainty of valid thresholds stemmed partly from the problems associated with the real ear technique, and these researchers emphasized the need for an objective method of bone vibrator calibration. One of the first attempts to calibrate a bone vibrator in an objective manner was done by knudsen and Jones (1931). A detailed description of their method is presented in the following excerpt: 
The aluminum rod of the bone conduction receiver is made to rest lightly on a small cylindric bearing taken from the movement of a watch. As the rod vibrates back and forth, it rocks the small cylindric bearing. A small concave mirror (less than $1 \mathrm{~mm}$. in diameter) was attached to the cylindric bearing. The light from a small straight filament lamp is placed near this small mirror, and the reflected light is focused on a graduated screen of translucent glass. Then as the aluminum rod of the receiver vibrates longitudinally, the image of the straight filament lamp is spread out on the screen, in an amount proportional to the amplitude of vibration of the rod. An optical-mechanical system was arranged in such a manner that the amplification of the motion of the rod was slightly more than one thousand fold. Even with this large magnification, it was not possible to obtain an appreciable reading on the glass screen at the minimal threshold of audibility. Accordingly, the amplitude of vibration of the rod was increased above the minimal threshold by a known amount - an amount which could be measured on the glass screen. Thus, by knowing to what extent the amplitude of vibration had been increased above the minimal threshold, it was possible to calculate the amplitude of vibration at the minimal threshold. - . It will be noted that the amplitude of vibration which must be communicated to the mastoid bone, in order that the tone be audible, is very small, varying from slightly more than $0.0000015 \mathrm{~cm}$. at 128 double vibrations [ $\mathrm{Hz}$ ] to $0.000000027 \mathrm{~cm}$. at 1,024 double vibrations [ $\mathrm{Hz}$ ]. (pp. 494-6)

As might be suspected, this procedure was impractical for the every-day calibration of a bone receiver in the clinic. Hawley (1939) working out of the Bell Laboratories was credited with developing the first "artificial mastoid" (Carlisle and Pearson, 1951; see Figure 6). Hawley emphasized that the load on the receiver had a definite effect on the response characteristic of the artificial mastoid. He also speculated that the rubber pad which simulated the human mastoid impedance would age and change the impedance 


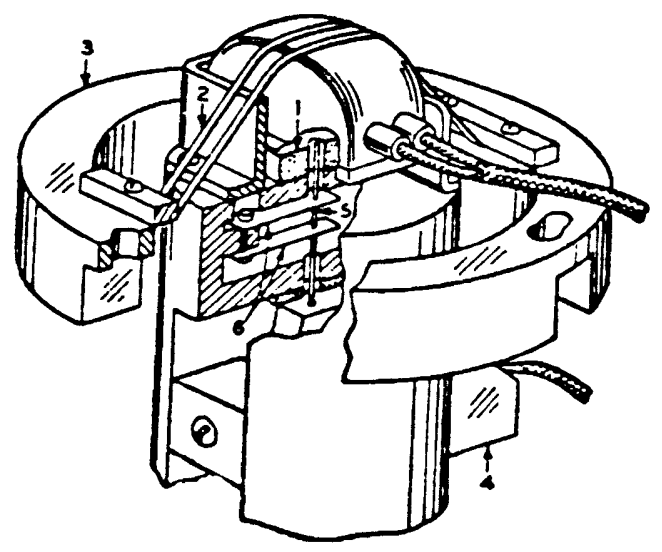

EIGURE 6. Diagrammatic drawing of the first Artificial Mastoid indicating operating parts: 1) Rubber block, 2) Rubber bands, 3) Angular weight, 4) Phonograph reproducer, 5) Supporting springs (Hawley, 1939). 
characteristics. But, he suggested, the replacement of the old pad with a new one was a simple matter.

This system, as criticized by Carlisle and Pearson (1951), utilized a drive rod which touched only one region of the bone vibrator, consequently it did not measure the total output of the bone vibrator. Carlisle and Pearson (1951) developed a strain-guage type artificial mastoio which consisted essentially of a stiff metal bar with a strain-sensitive transducer attached to the under side of a compliant viscoelastic pad (see Figure 7). The viscoelastic pad was composed of a plastic substance known as koroseal (a permaflex product) and Carlisle and Pearson believed this material simulated the mechanical impedance of the skin and headbones.

The viscoelastic material, however, as stated by weiss (1960), varied from "batch to batch" and was prone to vary its response characteristics respective to changes in age, temperature and humidity. Also, as Dirks (1978) pointed out, since very little information concerning the impedance of the human mastoid was available at that time, the artificial mastoid was only a first order approximation to the human mastoid.

The first stable, commercially available artificial mastoid was developed in the Beltone Research Laboratory and presented before The Acoustical Society of America in May of 1959 (Weiss, 1960). Weiss credited the 1955 work 


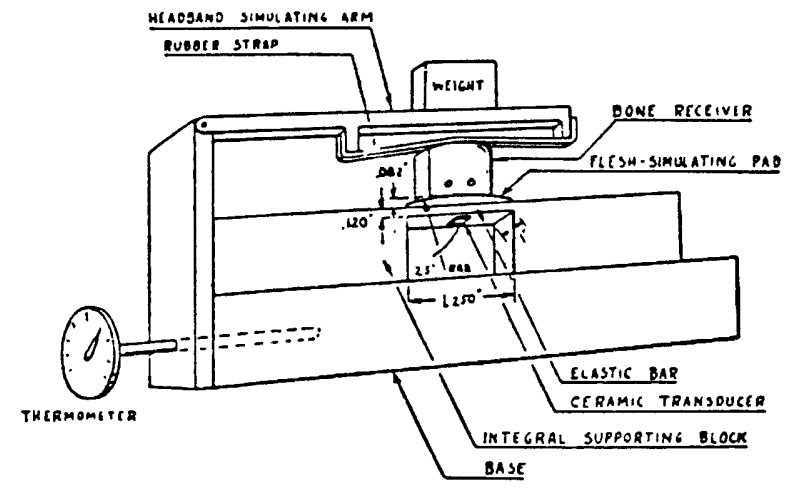

FIGURE 7. Schematic view of strain-gauge type Artificial Mastoid (Carlisle and Pearson, 1951). 
of Edith Corliss and Walter Koidan at The National Bureau of standards with investigating vibrational patterns of the skull under various conditions of driver size and coupling force. He also acknowledged the revisions in the data presented by Dr. Cook of The American Speech and Hearing Association in November, 1959 (Weiss, 1960).

Weiss stated that the Beltone $5 \mathrm{~A}$ (see Figure 8 ) was an air damped artificial mastoid which simulated the mechanical impedance of the human mastoid and employed no viscoelastic material. He claimed the instrument was virtually immune to aging defects and was easily reproducible. It was designed for the calibration of bone vibrators used in audiometers and bone conduction hearing aids (Weiss, 1960).

With the development of the first practical artificial mastoid, it became readily apparent that an agreement regarding the standardization of "normal" threshold by bone conduction was urgently needed (Wilbur, 1978). In the united States, the standards Committee of the Hearing Aid Industry Conference (HAIC) compiled data from nine different audiology clinics for the purpose of developing interim norms until which time that an international standard could be developed. As a result, the HAIC Interim Bone Conduction Norm for Audiometry was established in 1965 (Lybarger, 1966).

studebaker (1967) who participated in establishing the interim bone conduction norms was critical of these 


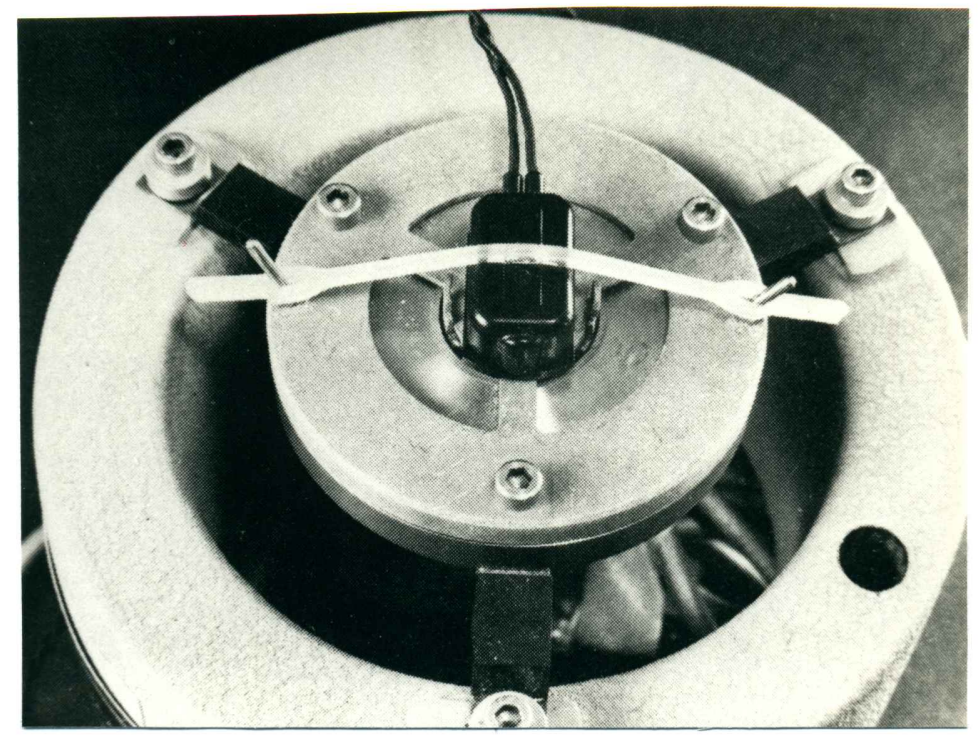

Figure 8. The Beltone Artificial Mastoid (Wilbur, 1974). 
HAIC values for several reasons. First, he observed that seven of the nine studies upon which the HAIC standard was based used clinical headbands while the other two used headbands of their own design. He demonstrated that the standard clinical headbands imparted approximately $300 \mathrm{gm}$ force at the mastoid, and that the Radioear B-70A, which he believed, was the most popular bone vibrator in the U.S. at that time, was extremely sensitive to changes in application force. He noted that Corliss and Koidan (1955) made their measurements of mastoid and forehead impedance with $500 \mathrm{gm}$ and $1000 \mathrm{gm}$ forces. Since the Weiss mastoid was based on these results, he argued, it was therefore important that the vibrators be applied to the head with at least $500 \mathrm{gm}$ of force.

secondly, studebaker reported that the method used to calculate the HAIC interim standard was the arithmetic mean of nine studies. The variance between these studies ranged from $15 \mathrm{~dB}$ to $21 \mathrm{~dB}$ at the different test frequencies. Further, studebaker noted that the distribution was quite skewed at the frequencies of 250 and $500 \mathrm{~Hz}$ with two of the nine studies reporting much lower values than the others. He contended that due to this wide variance, the median was a more appropriate statistical value.

Finally, studebaker criticized the HAIC standard in that it purported to be valid for both the Radioear B-70A and the sonotone B-9. His investigations (1967) demonstrated 
that a single standard could not apply to more than one model of bone vibrator, and future inquires must include the application force within the standard.

Dirks and Kamm (1975) restated studebaker's earlier concerns and added $1000 \mathrm{~Hz}$ to the list of HAIC frequencies which have questionable validity for the B-70A. Dirks and Kamm also reported values for the new Radioear $B-71$ and $B-72$ on both the Betone 5A and the European Bruel and Kjaer 4930 artificial mastoid (see Table I).

The Bruel and Kjaer 4930 artificial mastoid was designed by stisen and Dahm and used during the 1960 s in England and Europe (Dirks, 1978). This apparatus (see Figure 9) was constructed so that each of the major components simulates some part of a human head. The seismic mass which is a large nickel plated cylinder represents the mass of the human head. The loading mass which is a teflon pin at the vertical center of the seismic mass lies beneath two rubber domed caps and duplicates as nearly as possible the complex action of the skin under a vibrational load (Bruel and Kjaer, 1974). The concept of a proper vibrational load was adaressed by Hawley (1939). He demonstrated that the response of a bone vibrator depends on the load against which it works, or in this case, the surface upon which it rests.

In their investigation, Dirks and Kamm (1975) demonstrated that, with the input voltage to the various bone vibrators held constant, the $B$ \& K mastoid generates 


\section{TABLE I \\ RESULTS OF THE BONE CONDUCTION DATA ACCUMULATED AT THE UNIVERSITY OF CALIFORNIA AND THE VETERANS ADMINISTRATION HOSPITAL IN LOS ANGELES, CALIFORNIA BY DIRKS AND KAMM 1975}

Re: Beltone 5A Re: $B$ and $K 4930$

\begin{tabular}{|c|c|c|c|c|c|c|c|c|c|c|c|}
\hline \multicolumn{2}{|c|}{ Condition } & 0.25 & 0.50 & 1.0 & 2.0 & 4.0 & 0.25 & 0.50 & 1.0 & 2.0 & 4.0 \\
\hline$B-70 A$ & $\begin{array}{l}\text { UCLA } \\
\text { VAHLB } \\
\text { Combined }\end{array}$ & $\begin{array}{l}48.8 \\
50.8 \\
49.8\end{array}$ & $\begin{array}{l}42.1 \\
46.6 \\
44.4\end{array}$ & $\begin{array}{l}30.3 \\
29.1 \\
29.7\end{array}$ & $\begin{array}{l}18.8 \\
25.1 \\
22.0\end{array}$ & $\begin{array}{l}18.9 \\
15.1 \\
16.8\end{array}$ & $\begin{array}{l}47.5 \\
47.9 \\
47.7\end{array}$ & $\begin{array}{l}38.4 \\
38.5 \\
38.5\end{array}$ & $\begin{array}{l}24.0 \\
24.0 \\
24.0\end{array}$ & $\begin{array}{l}10.2 \\
12.9 \\
11.5\end{array}$ & $\begin{array}{l}14.8 \\
14.1 \\
14.5\end{array}$ \\
\hline$B-71$ & $\begin{array}{l}\text { UCLA } \\
\text { VAHLB } \\
\text { Combined }\end{array}$ & $\begin{array}{l}48.7 \\
48.2 \\
48.5\end{array}$ & $\begin{array}{l}46.6 \\
49.8 \\
48.2\end{array}$ & $\begin{array}{l}27.8 \\
29.2 \\
28.5\end{array}$ & $\begin{array}{l}21.4 \\
27.0 \\
24.2\end{array}$ & $\begin{array}{l}19.9 \\
17.1 \\
18.5\end{array}$ & $\begin{array}{l}47.6 \\
47.4 \\
47.5\end{array}$ & $\begin{array}{l}37.0 \\
40.8 \\
38.9\end{array}$ & $\begin{array}{l}22.5 \\
24.5 \\
23.5\end{array}$ & $\begin{array}{r}6.7 \\
13.5 \\
10.1\end{array}$ & $\begin{array}{l}12 \cdot 3 \\
14 \cdot 4 \\
13 \cdot 4\end{array}$ \\
\hline$B-72$ & $\begin{array}{l}\text { UCLA } \\
\text { HAIC }\end{array}$ & $\begin{array}{l}48.7 \\
43.0\end{array}$ & $\begin{array}{l}44.1 \\
37.5\end{array}$ & $\begin{array}{l}27.4 \\
23.0\end{array}$ & $\begin{array}{l}24.6 \\
20.0\end{array}$ & $\begin{array}{l}15.5 \\
15.0\end{array}$ & $\begin{array}{l}47.0 \\
41.4\end{array}$ & $\begin{array}{l}38.3 \\
30.7\end{array}$ & $\begin{array}{l}22.5 \\
16.9\end{array}$ & $\begin{array}{l}8.1 \\
8.1\end{array}$ & $\begin{array}{r}6.8 \\
11.2\end{array}$ \\
\hline
\end{tabular}




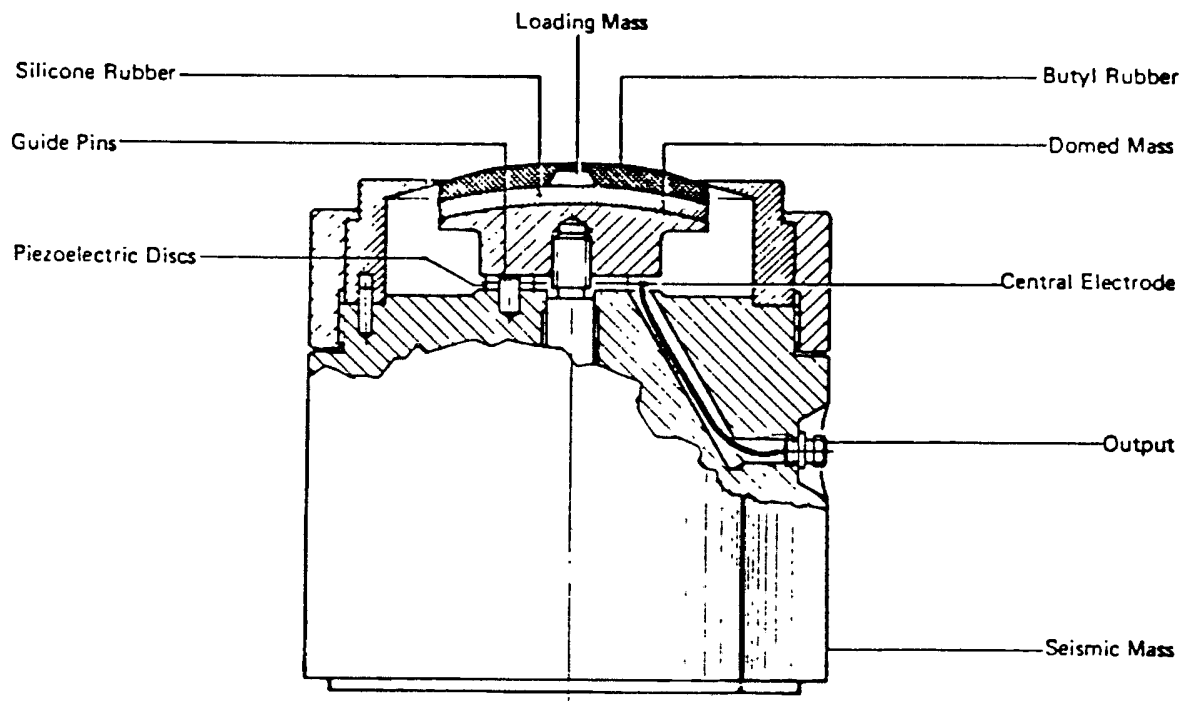

EIGURE 9. Cutaway view of the Bruel and Kjaer Artificial Mastoid (Bruel and Kjaer Instruction Manual, I974). 
consistently lower force levels than the Beltone 5A. This appears to be the only reported significant difference between the two mastoids. However, since neither of these two artificial mastoids conform exactly to current ANSI standards, and no international agreement as to the exact physical characteristics of artificial mastoids has been established (Wilbur, 1978), it appears the choice of one or the other is a matter of personal preference.

For nearly a decade, the HAIC Interim Standards have provided valuable normative data as a guideline for the calibration of bone vibrators used in audiometry. However, with the development of the $1.75 \mathrm{~cm}^{2}$ area contact tip vibrators, it may be prudent and practical, in this author's view, to calibrate these new vibrators (B-71, B-72 and Oticon A-20) as specified by Dirks and Kamm (1975) and Dirks (1978). However, the calibration of the $\mathrm{B}-70 \mathrm{~A}$ is a different matter. The HAIC values for this vibrator may indeed be inaccurate as Studebaker (1967), Dirks and Kamm (1975) and Dirks (1978) suggest, but wilbur (1978) stresses the importance of professional standardization and the continued use of the HAIC bone conduction values for the B-70A. In conclusion, the HAIC values for the Radioear B-70A and Sonotone B-9 should continue to be employed until such time that a new standard is adopted. Since the bone vibrators with a $1.75 \mathrm{~cm}^{2}$ area contact tip are not covered by the HAIC values, it would seem appropriate to use the calibration values presented 
by Dirks and Kamm (1975) and Dirks (1978). The variability of bone conduction measurements may be reduced by employing the following procedures (ANSI, 1972):

1) Placement of the bone vibrator on the mastoid process;

2) Leave the test ear unoccluded; and

3) Use narrow bands of masking noise in the contralateral ear at an effective masking level of $30-35 \mathrm{~dB}$.

\section{SPEECH BY BONE CONDUCTION}

When one hears one's own voice, it is through the bone conduction pathway of the head. Bekesy (1949) demonstrated that bone conducted sounds reach the ears from the larynx primarily along the vertical axis of the head. The vibrations of the skull during speech is caused not only by the vertical vibrations of the edges of the vocal folds, Bekesy reported, but also by the sound pressure in the mouth. This sound pressure produces vertical vibrations of the lower jaw and skull.

The bone conduction pathway, Bekesy (1949) stated, attenuates high frequencies more than low frequencies. This also accounts for the fact that one's own recorded voice often sounds tinny and lacks character because the head is a low pass filter (Tonndorf, 1972).

It should be noted that the bone conduction channel was the first and only method of aiding the hearing impaired 
(Berger, 1975). Berger reports that from the early 1500's through the late 1800 's the usefulness of rods, sticks, and other bone conduction hearing devices were "discovered," and "rediscovered." Figure 10 shows one such device called the Fonifero developed by Giovanni Paladino in 1876. A more popular device used through the early 1900's was the "hearing fan" (see Figure 11). This device which was clasped between the teeth and collected the air borne sounds was developed by Richard Rhodes in 1879 (Berger, 1975). Although these devices provided some benefit to the hearing impaired (largely those with conductive losses), there is no report in the literature of their use in a medical diagnostic setting.

Pohlman (1929) was the first researcher to report the use of bone conducted speech as a clinical measure. He reasoned that voice sounds were complicated combinations of tones and tuning forks which produced single pure tones were a poor tool for the assessment of speech sensitivity. Utilizing a Western Electric audiometer equipped with a phonograph, Pohlman was able to increase the output at the surface of the bone receiver by adding a second amplifier to the speech circuit. Air conducted speech testing was determined by holding the bone receiver by its mushroom stem against a resonant surface, such as a table, and the patient was instructed to write down the numbers he heard which were progressively attenuated. This procedure was repeated with the same receiver held against the forehead to determine 


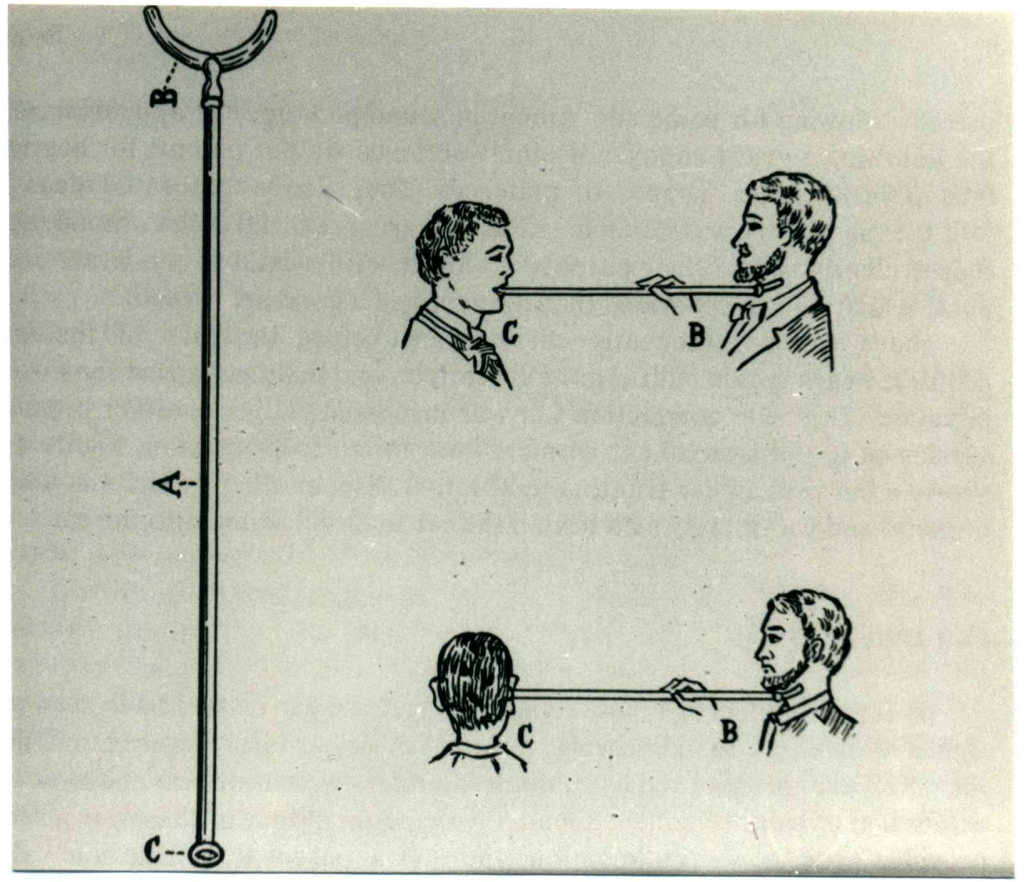

Figure 10. The Fonifero (Berger, 1975). 


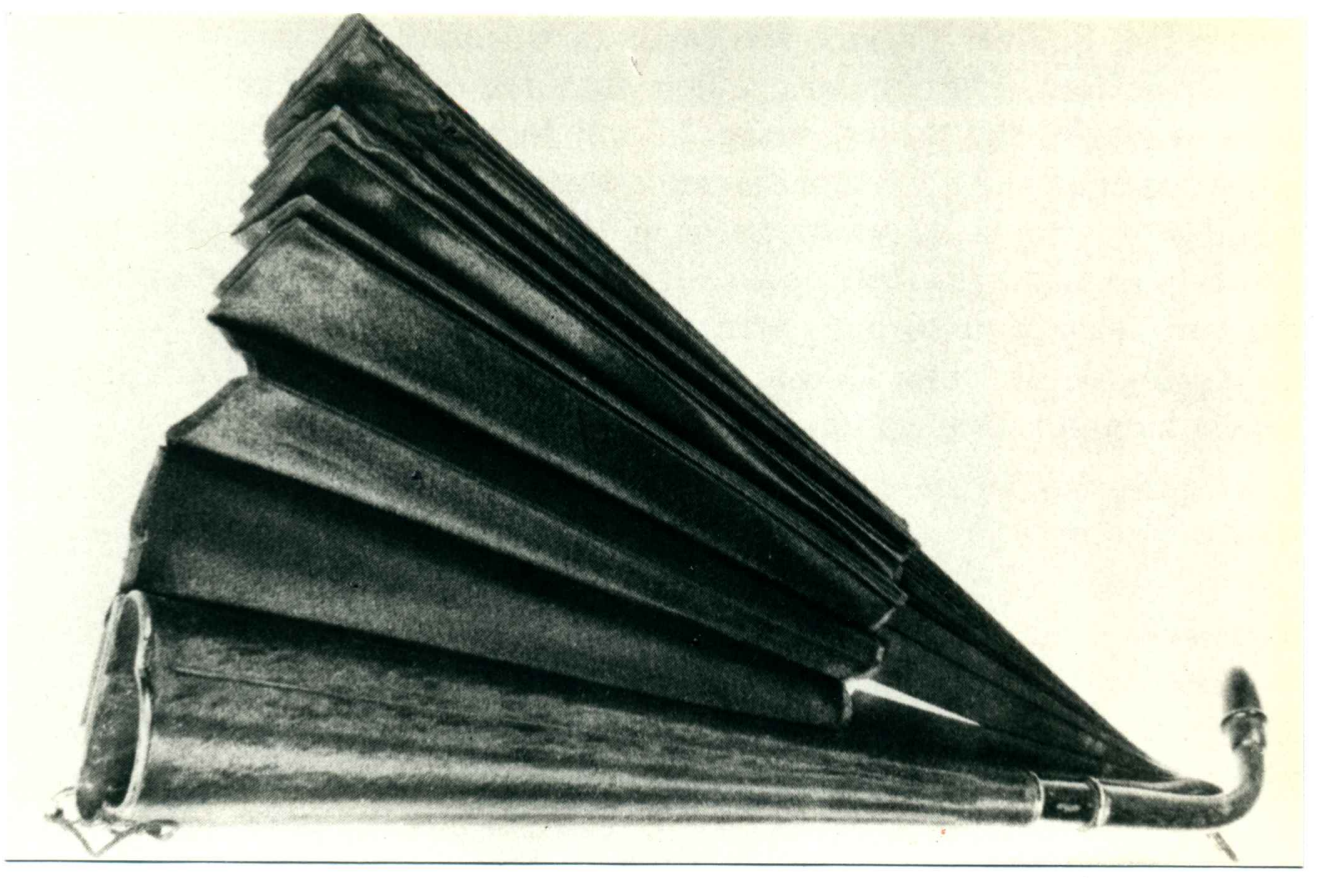

Figure 11. The Hearing Fan (Berger, 1975). 
the bone conduction speech results. Pohlman believed it was advantageous for purposes of comparison to use the same receiver for both air and bone sensitivity. He also argued strongly against the use of live voice testing, and speech stimuli that required subjective responses contingent on the subjects intelligence (Pohlman, 1931).

Jones and Knudsen (1936) also emphasized the importance of performing "speech articulation tests" by both air and bone conduction with hearing aid candidates. These investigators compared the air and bone conducted articulation results for both vowels and consonants. Jones and knudsen suggested that selective amplification was now possible by conducting speech discrimination tests through either a high pass, low pass, or uniform pass mode.

Watson (1937) further investigated speech articulation by bone conduction. Utilizing the older grenade-shaped electrodynamic bone vibrator (see figure 12), $370 \mathrm{gm}$ application force at the forehead, and $.665 \mathrm{~cm}^{2}$ area of vibrator surface contact, Watson developed an articulation curve relative to intensity of the speech signal. He used a phonograph recording to deliver the single syllable words, and the bone conduction discrimination results shown on Figure 13 were generated by watson himself, acting as his only subject. Also included in Figure 13 (note the dotted line) is a comparison intelligibility curve for normal hearing individuals by air conduction (steinberg, 1929). The 


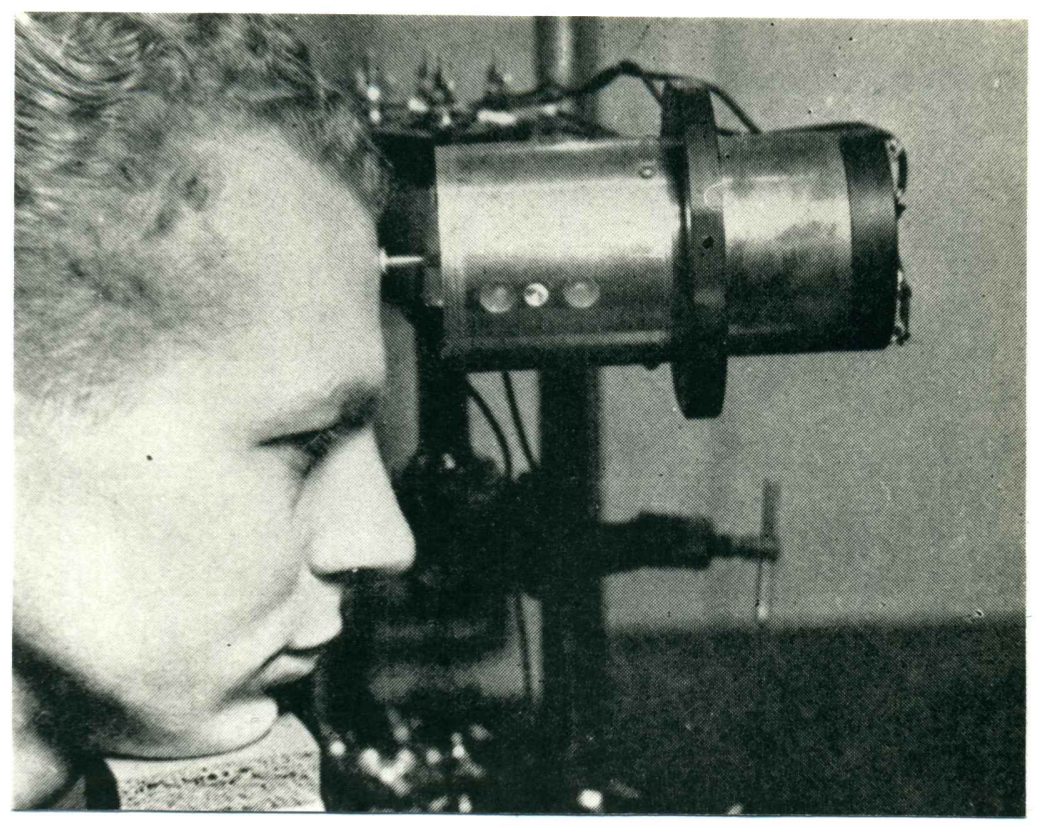

Figu들 12 . Watson demonstrating the use of his bone vibrator (1937). 


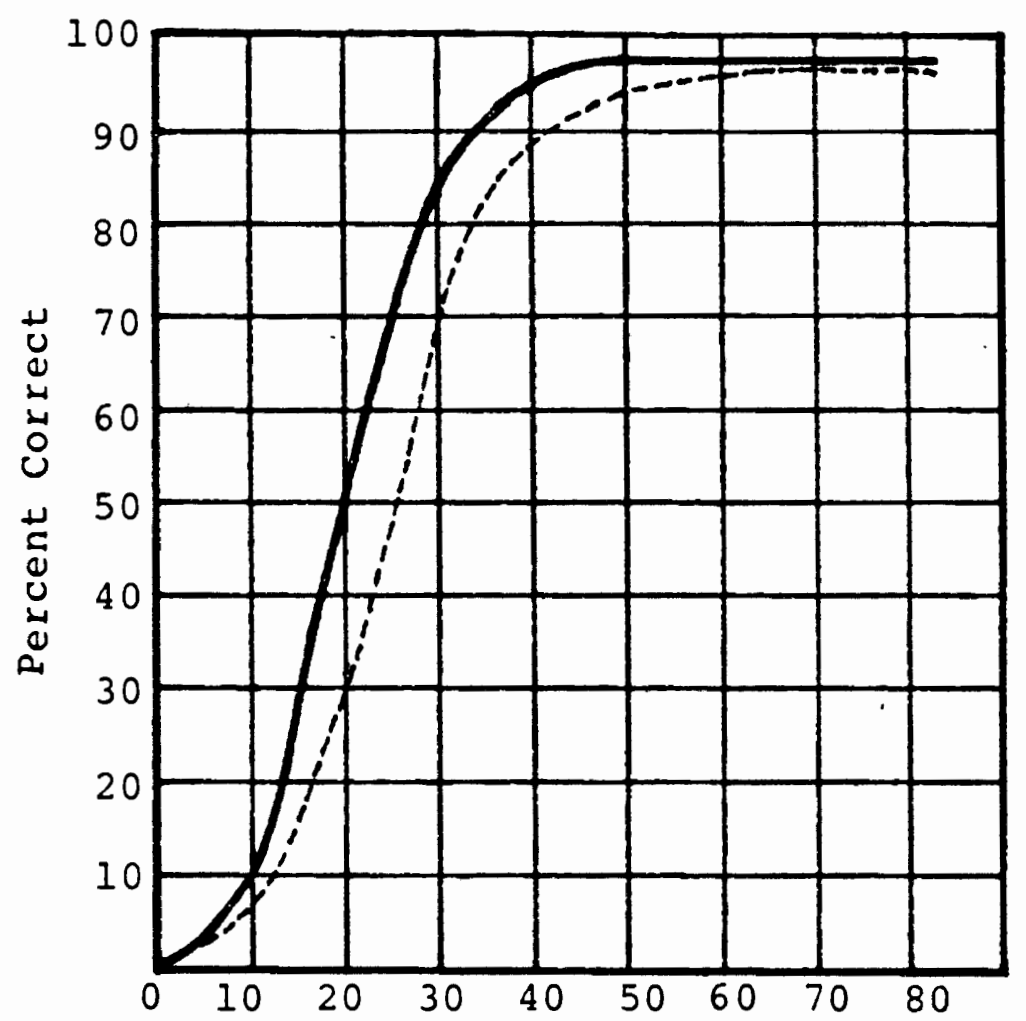

Decibels Above Threshold Level

FIGURE 13. The solid black line represents the articulation function for a single observer by air conduction in the monaural and binaural condition, and by bone conduction with the ear canals occluded and unoccluded. All four curves coincided (Watson, 1937).

The dotted line represents the articulation function for monaural air conduction developed by Steinberg (1929). 
Steinberg curve was produced by using single syllable nonsense words and employed a group of trained listeners as subjects.

Watson (1937) hypothesized that since his air and bone conduction articulation scores (for monaural and binaural conditions) were similar, the ability to understand speech depended primarily on the level of intensity above threshold. It should be noted here that watson defined his " $O$ " dB speech threshold as that level at which speech was just barely audible but not understandable. Furthermore, he reasoned that for normal listeners a large amount of frequency distortion was tolerable utilizing bone conduction apparatus.

Tato and Alfaro (1949) investigated 51 subjects in an effort to establish an articulation curve by bone conduction for normal hearing individuals and those suffering from different types of hearing loss. Due to the problems of calibration and subject variability, these authors mentioned they were not alone in their scepticism of pure tone bone conduction results. Tato and Alfaro suggested the utilization of speech discrimination would enhance test validity by bone conduction. They reported that bone conducted speech discrimination scores delivered at a comfortable listening level were extremely diagnostic as to the degree of sensorineural impairment. They considered operable any patient who scored above 80 percent correct. 
Goetzinger and Proud (1955) studied the feasibility of employing the speech reception threshold by bone conduction as a supplementary measure to the pure tone bone conduction test. They collected data on 353 ears of patients ranging in age from 5 to 64 years. The relationship by bone conduction between the speech reception threshold and the pure tone average showed a high $(\underline{r}=0.90)$ positive correlation. By comparison, these authors reported a positive correlation of $(\underline{r}=0.92)$ between the average pure tone threshold and the speech reception threshold by air conduction.

Goetzinger and proud recommended utilizing bone conducted speech reception threshold testing with young children with possible conductive impairments, and in the prediction of suitable cases for fenestration surgery. Furthermore, they reported administering speech discrimination tests by bone conduction at $25 \mathrm{~dB}$ above the speech reception threshold. At this sensation level using monitored live voice, a score of 90 - 100 percent was appropriate for persons with normal hearing and conductive impairments while persons with sensorineural impairments exhibited varying degrees of discrimination difficulty.

In Germany, Hahlbrock (1962) demonstrated that tactile "feeling" thresholds which seem to appear for frequencies up to $1000 \mathrm{~Hz}$ in patients with severe to profound hearing losses may be detected by bone conducted speech testing. 
He suggested that PB-lists (phonetically balanced monosyllabic words) could be presented at several different sensation levels for both air and bone conduction, respectively. In this manner, two different audiograms would be recorded, one for pure tones which established the hearing loss and one for speech which displayed the discrimination loss (see Figures 14 and 15). In Figure 14, the pure tone air and bone thresholds are validated by the separation between the air and bone conducted speech discrimination curves. However, in Figure 15, the pure tone audiogram is the same as in Figure 14 but the air and bone discrimination curves overlap indicating a pure sensorineural impairment and invalid pure tone bone conducted thresholds. The exact diagnosis and need for surgical intervention, Hahlbrock summarized, may be determined only with the help of bone conduction speech audiometry.

Miller (1964) utilized bone conducted speech reception threshold testing with masking to detect individuals feigning a unilateral hearing loss. Miller determined that the speech reception threshold by bone conduction with a forehead placement was $45 \mathrm{~dB}$ with reference to the average normal "O" HL (hearing level) by air conduction. This difference of $45 \mathrm{~dB}$ represents, primarily, the attenuation of energy through the bone conduction circuitry and receiver.

Robinson and Kasden (1970) reported bone conducted speech discrimination results on 67 otosclerotic patients 
$X-X$ A1r Conduction $\quad<\cdots \cdots<$ Bone Conduction

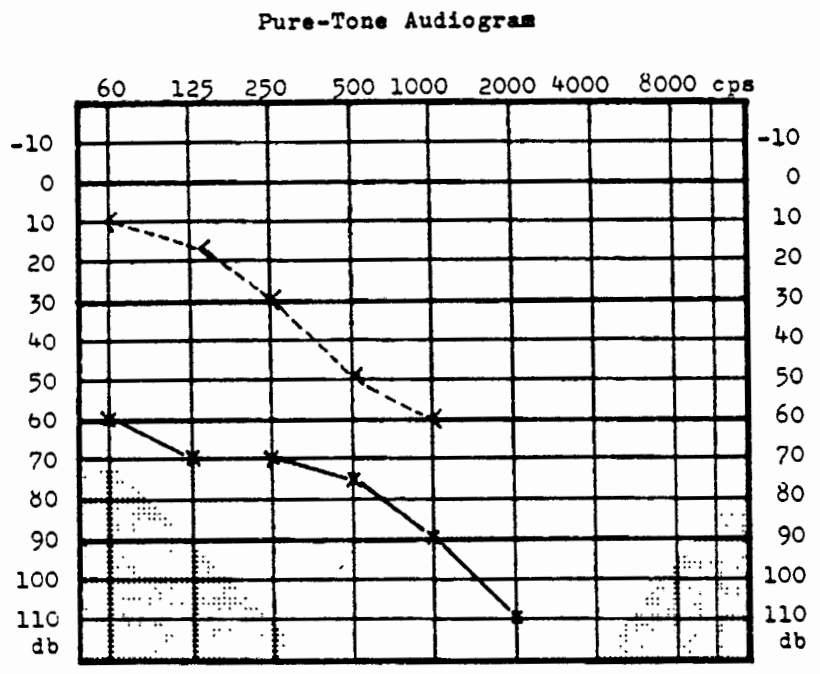

Speech-Audiogram

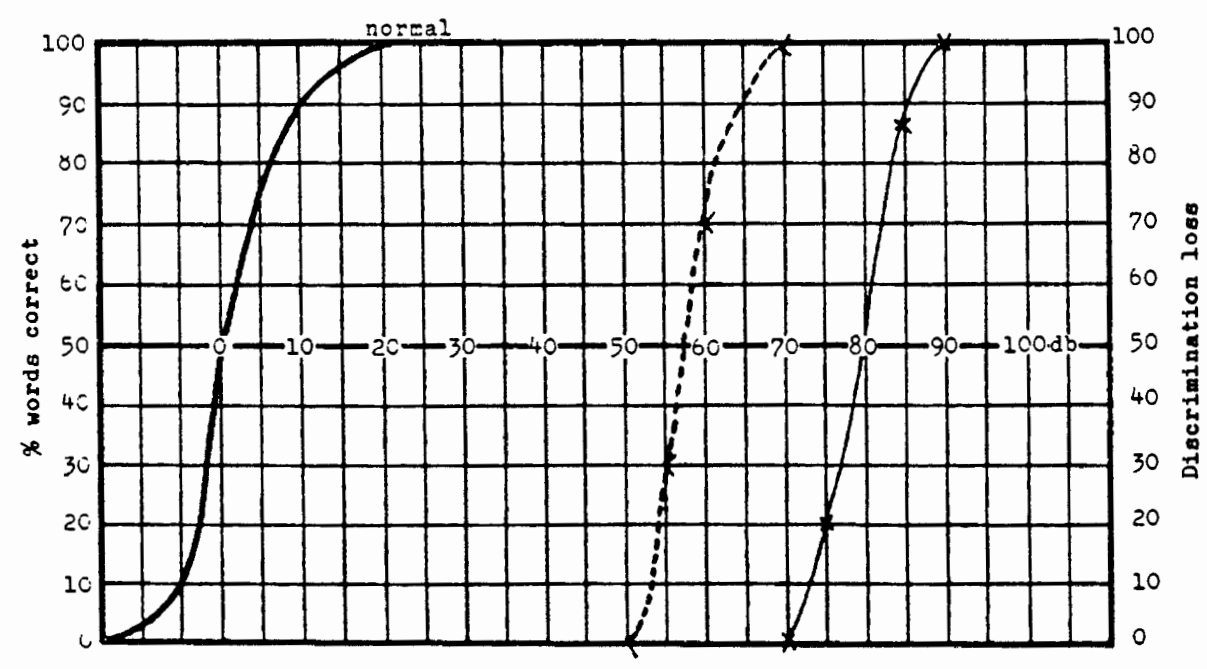

EIGURE 14. The pure tone audiogram reveals an air bone gap and speech audiometry by air and bone conduction confirms the presense of a conductive component. Assessment - mixed loss of hearing (Hahlbrock, 1962). 
$X-X$ Air Conduction

$\leftarrow-\cdots<$ Bone Conduction
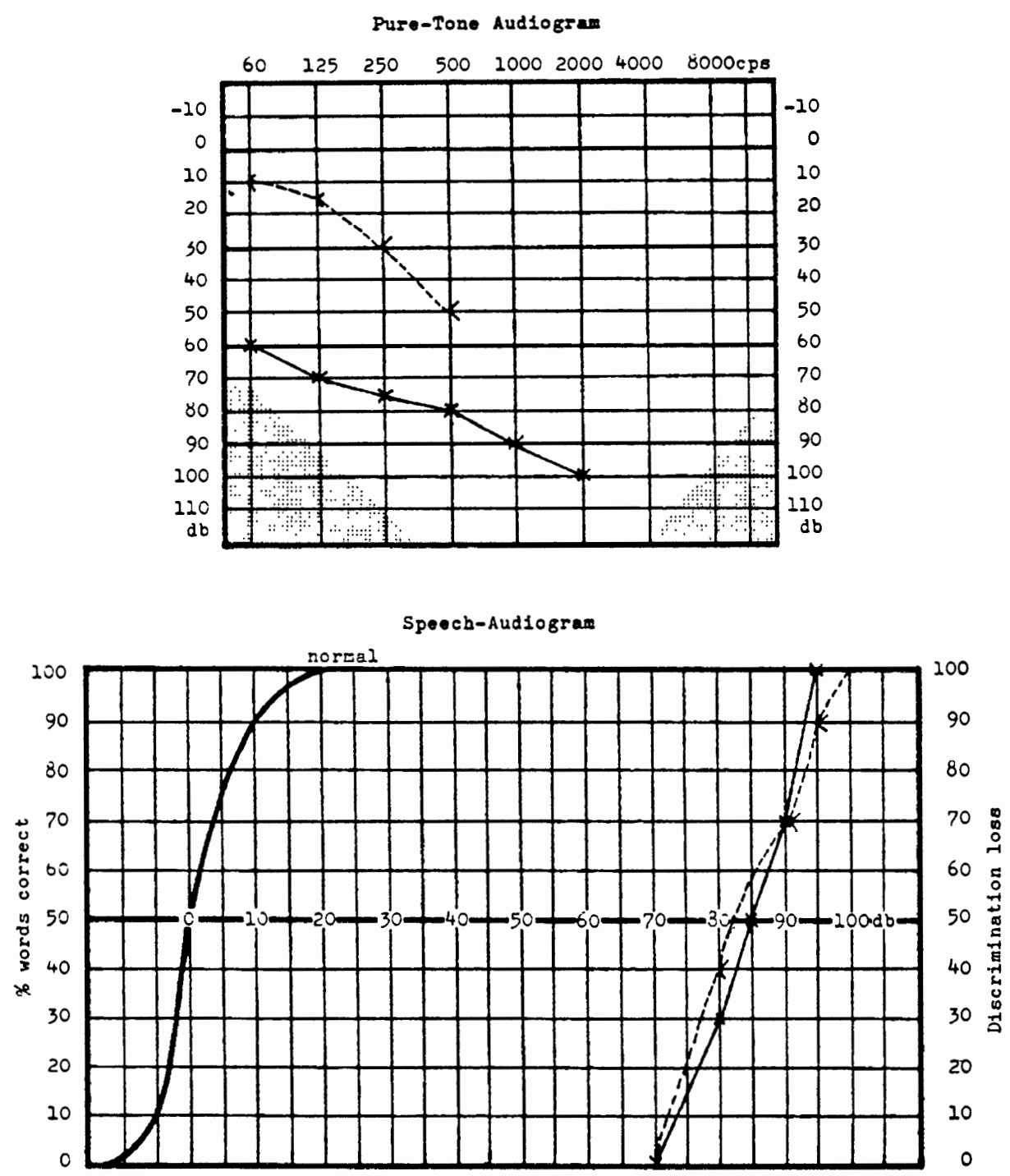

EIGURE_15. An almost identical pure tone audiogram to the one in Figure 14 is shown to be invalid. Speech discrimination scores by air and bone conducton overlap and indicate that the pure tone audiogram registered tactile thresholds. Assessment - sensorineural loss of hearing (Hahlbrock, 1962). 
and illustrated that pre-operative bone conduction scores were more accurate for assessing cochlear reserve than air conducted speech discrimination results. (These investigators utilized a B-70A vibrator with an additional in line amplifier.) Subsequently, Kasden and Robinson (1973) were unable to demonstrate the value of bone conducted speech discrimination tests on patients with conductive pathologies other than otosclerosis. The results for otoscerotics were explained on the basis that ossicular fixation changed the frequency response and transformer mechanics of the middle ear thus affecting air conduction speech audiometry. More recently, Robinson and Kasden (1977) employed bone conduction speech testing to demonstrate that a hearing loss immediately following middle ear surgery was generally not due to a cochlear involvement, but rather to factors directly related to the surgery in the tympanic cavity.

Hicks (1972) in possibly the earliest published study related to children introduced the case of a four year child whose pure tone results by air and bone conduction appeared to demonstrate a pure sensorineural hearing loss. However, upon reviewing the results gained by air and bone conducted speech reception threshold testing, it was apparant that the hearing loss was primarily conductive in nature.

Merrell, et al. (1973) involving a sample of 64 children demonstrated the usefulness of bone conducted speech audiometry to diagnose conductive hearing losses in children 
ages 4 to 9 years. In this study, the bone conducted speech $\mathrm{HL}$ setting was calibrated using normal hearing, college-aged individuals and was found to be $40 \mathrm{~dB} \mathrm{HL}$ utilizing a $\mathrm{B}-70 \mathrm{~A}$ vibrator at the mastoid placement.

Using similar apparatus, stockdell (1974) reported audiometric zero for speech by bone conduction to be 38.4 $\mathrm{dB} H L$. Valente and stark (1977) while investigating the value of bone conduction speech audiometry in children with various hearing impairments, determined the "zero" reference level to range from 25-50 dB HL with a mean of $39.3 \mathrm{~dB} H L$. Scrinivasan (1974), the first researcher to use an oscillator (see Figure 16) conforming to current ANSI (1972) standards with an application force of $5.4 \mathrm{~N}$ demonstrated that the speech reception threshold by bone conduction was highly correlated with the pure tone average by both air and bone. Further, it was found to be equally correlated with the air conducted speech reception threshold for normal hearing individuals. These high correlations persisted when performed on both individuals with conductive and sensorineural hearing losses. The conductive group demonstrated the largest correlation, while the sensorineural individuals with precipitous losses demonstrated the lowest positive correlation between air and bone speech results.

Klodd and Edgerton (1977) found that bone conduction speech testing from the mastoid position was superior to the forehead position for two reasons. First, the effective 


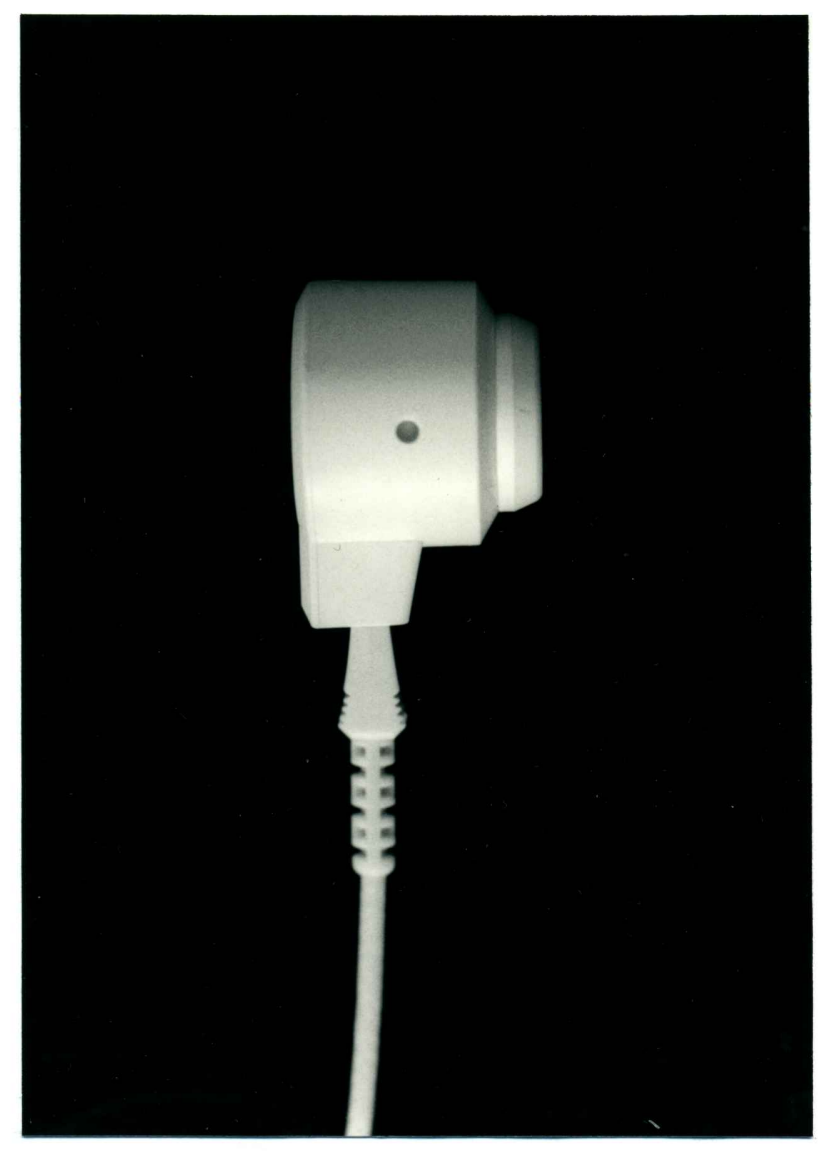

Eigure 16. The Oticon A-20 bone vibrator with a circular contact area of $1.75 \mathrm{~cm}^{2}$. 
range of the bone vibrator output is greater at the mastoid than the forehead position, and secondly, the occlusion effect is smallest at the mastoid position. These researchers utilizing a B-70A bone vibrator found the occlusion effect for bone conducted speech was approximately $18 \mathrm{~dB}$ at the mastoid position and $23 \mathrm{~dB}$ when testing from the forehead position.

Barry and Geddis (1978) investigated the useful output limit of the B-70A bone vibrator for speech audiometry. "Zero" $d B$ HL for the calibration of bone-conducted speech was $64.7 \mathrm{~dB}$ SPL at $500 \mathrm{~Hz}$ which these investigators believed to be approximately equal to the $40 \mathrm{~dB}$ HL setting that previous researchers had indicated for normal bone conducted speech reception. The speech discrimination scores were obtained utilizing recorded Northwest University (NU-6) word lists at $\mathrm{HL}$ settings corresponding to $20,40,60,70$, and $80 \mathrm{~dB} \mathrm{HL}$. The mean articulation function for the ten normal listeners at each dial setting is displayed on Figure 17. As can be seen on this graph, a nonlinear relationship between intensity and intelligibility has developed at $50 \mathrm{~dB} \mathrm{HL}$ and by $80 \mathrm{~dB}$ HL total harmonic distortion (100 percent) was evident. These authors suggested that the implementation of the B-72 vibrator might favorably enhance the intensity vs intelligibility ratio due to its increased output at 250 $\mathrm{Hz}$.

In summary, it appears that bone conduction speech 


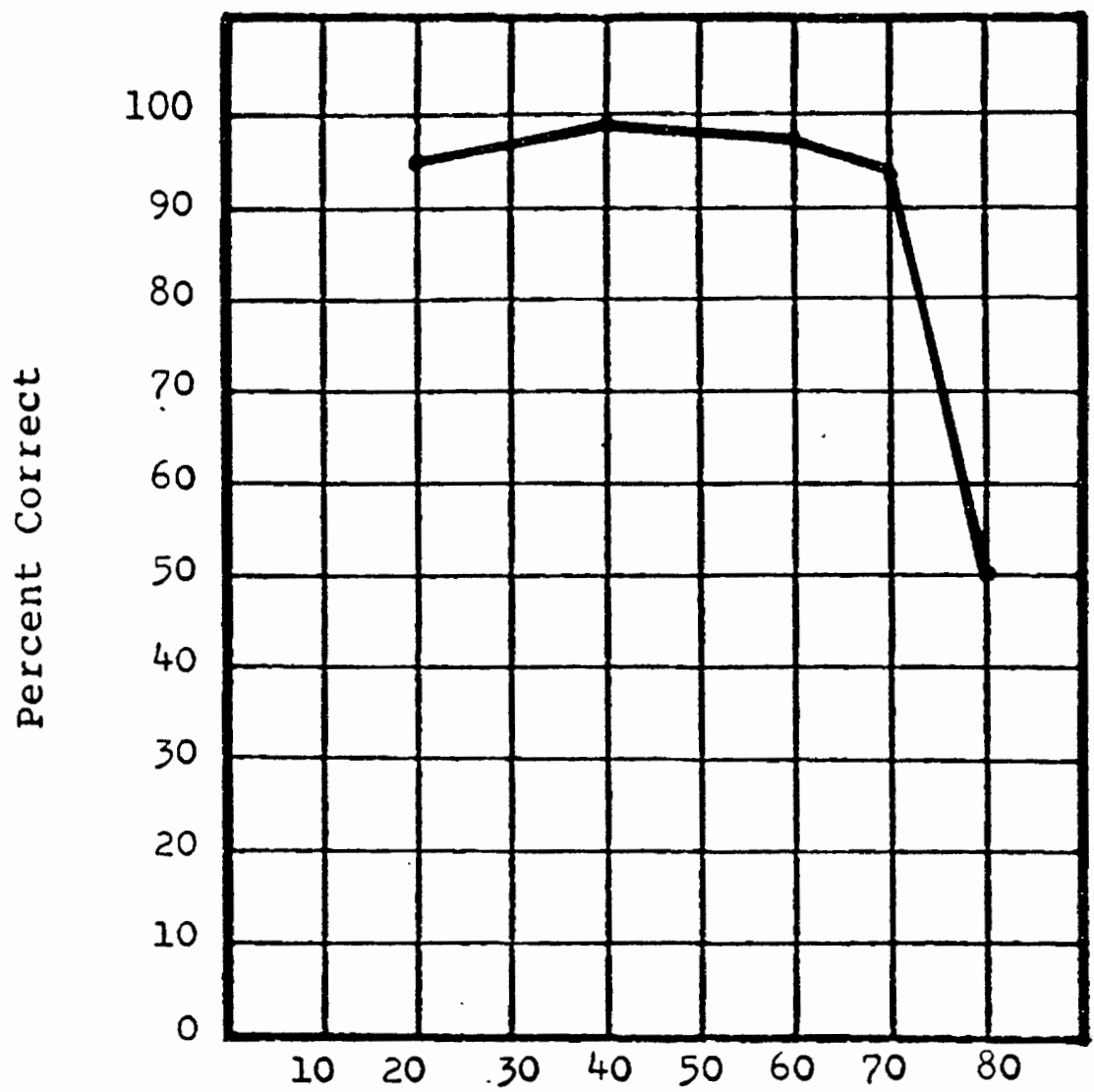

Decibels Hearing Level (HL)

EIGURE 17. Articulation gain function for bone conducted speech using a Radioear B-70A vibrator (Barry and Geddis, $1978)$. 
audiometry has had a sporadic and diverse developmental history. Most of the early studies cited used equipment which was personally constructed by the researcher and, generally, lacked universal application. The later studies appeared to be in agreement on the value of bone conducted speech reception testing as a means to validate bone conducted pure tones; especially when assessing children and other difficult to test patients. Speech discrimination testing by bone conduction has been shown to be valuable for screening appropriate candidates of middle-ear surgery, however, the recent work of Barry and Gaddis (1978) has questioned the validity of this measurement when used at high intensities.

\section{PURPOSE}

The purpose of this study was to: 1) establish a normal intensity level for speech reception utilizing a B-72 vibrator; and 2) obtain a normal speech discrimination function for the B-72 Radioear bone vibrator.

\section{Rationale}

To date, there has been only one published investigation (Scrinivasan, 1974) utilizing bone conduction apparatus which followed the ANSI (S3.13-1972) guidelines specifying a plane circular contact tip area of $1.75 \mathrm{~cm}^{2}$. Furthermore, there has not been any published study regarding the speech performance of the B-72 Radioear bone vibrator.

The $B-7,2$ bone vibrator has been shown to be superior 
to the B-70A (Dirks \& Kamm, 1975) due to its high output and low harmonic distortion at $250 \mathrm{~Hz}$. The B-72 contains an additional mechanical network which lowers the frequency of the resonant peak to $250 \mathrm{~Hz}$, thereby generating an output at $250 \mathrm{~Hz}$ which is $20 \mathrm{~dB}$ greater than the $\mathrm{B}-70 \mathrm{~A}$ (Dirks and Kamm, 1975). Consequently, many audiometers in use today which utilize a $B-70 A$ bone vibrator can not generate enough output at $250 \mathrm{~Hz}$ to meet the HAIC interim bone calibration standards (Barry, 1980).

The performance of the B-72 Radioear bone vibrator as it relates to speech testing is largely unknown. Thus, it seems propitious to investigate the speech reception threshold and speech discrimination function by bone conduction utilizing the $\mathrm{B}-72$ bone vibrator. 
CHAPTER III

METHODS

\section{Subjects}

Twenty-six normal hearing subjects were selected from the Portland state University student population. No subject was used in this study who had reported a familial history of deafness, a positive record of ear disease or manifested any abnormal hearing thresholds or auditory processing difficulty. Further, the speech reception threshold by air conduction was within $10 \mathrm{~dB}$ HL of the average pure tone threshold for each ear. Speech discrimination results when delivered at a comfortable listening level achieved a score of at least 90 percent correct for the test ear and an acceptable difference between each ears' performance was no greater than 10 percent. In addition, each subject had an auditory sensitivity within $10 \mathrm{~dB}$ of audiometric zero (ANSI, 1969) for the test ear and within $15 \mathrm{~dB}$ of audiometric zero for the nontest ear for the octave test frequencies of 0.25 $4.0 \mathrm{kHz}$. A $-20 \mathrm{~dB}$ pad was used to establish the exact pure tone threshold value for each ear. 


\section{Procedure}

All potential subjects were given an audiological assessment utilizing standard clinical procedures, and every subject completed a case History form to confirm his or her eligibility for this investigation. Only the ear achieving the best average pure tone threshold and speech discrimination results by air conduction was used. Each of the subjects was assigned an individual number to maintain anonymity for all experimental data collected.

Prior to the adminstration of the experimental test, the subjects were seated at a desk in the audiological test suite and the instructions for the bone conduction speech reception threshold test were presented to each subject on a printed card. These instructions were read aloud to each subject and they were given an opportunity to ask questions concerning any aspect of the experimental procedure. The bone conduction oscillator was placed on the mastoid process behind the test ear, and the bone conducted speech reception threshold test was administered in the test suite. The subjects were instructed in a similar manner before the administration of the bone conducted speech discrimination tests and they were provided with answer sheets for their written responses. To prevent the possible intervening effects of a temporary threshold shift a minimum five minute rest period was mandatory whenever a test was delivered at a sensation level higher than the 
test immediately subsequent. Further, a miniumum rest period of fifteen minutes was required after the initial auditory assessment before the onset of data collection.

speech noise, which as a spectral composition limited to the speech frequencies ( 500 through $2000 \mathrm{~Hz}$ ), was used to mask the non-test ear. The intensity of the speech masking noise in the non-test ear was determined by adding $30 \mathrm{~dB}$ of effective masking to the sensation level of the experimental stimuli being presented to the ear under test. This level was sufficient to overcome the approximate $18 \mathrm{~dB}$ HL occlusion effect and still provide a favorable signal to noise ratio $(10-20 \mathrm{~dB})$ in the test ear.

All bone conducted speech testing material consisted of pre-recorded $\mathrm{W}-2$ spondaic word lists and 16 pre-recorded monosyllabic $\mathrm{NU}-6$ speech discrimination word lists (Auditec of st. Louis). The bone conducted speech discrimination tests were administered in $5 \mathrm{~dB}$ increments from the level of the bone conducted speech reception threshold or $0 \mathrm{~dB}$ sensation level (SL) to $30 \mathrm{~dB}$ SL, and from $90 \mathrm{~dB} \mathrm{HL}$ through $100 \mathrm{~dB} H L$. The sensation levels were selected in random order utilizing a table of random numbers (Mendenhall, 1975).

\section{Instrumentation}

All tests were conducted in a double walled sound treated room (International Acoustics Corporation, Model 
1403) and through a dual channel clincal audiometer (Maico, Model 24B). All air conducted stimuli were presented through a standard clinical set of earphones (Telephonics, Model TDH-39) mounted in foam rubber cushions (Acoustic Research, Model MX 4I/AR). A standard clinical bone conduction oscillator (Radioear, Model B-72) was utilized to deliver all experimental stimuli. Speech test material consisted of prerecorded $\mathrm{NU}-6$ word lists (Auditec of St. Louis) delivered to the audiometer by a reel-to-reel stereo tape recorder (Sony, Model TC-377). The audiometer's calibrated tape circuit was utilized to insure the electrical and acoustic integrity of all experimental stimuli.

\section{Calibration}

The audiometer calibration for bone conducted pure tones was checked prior to each experimental session. The output at the earphones for both right and left channels was electro-acoustically calibrated prior to testing the Ist, 10 th, 20 th and 30 th subject to reflect current ANSI standards using a precision sound level meter (Bruel and Kjaer, Model 2203) and an artificial ear (Bruel and Kjaer, Model 4152). A prerecorded segment of a $1000 \mathrm{~Hz}$ pure tone was utilized to calibrate the speech circuit. The output of the bone conduction vibrator was electroacoustically calibrated utilizing the artificial mastoid (Bruel and 
Kjaer, Model 4930) and adjusted to reflect the most recent calibration data established at the portland state University Audiology Clinic by the real ear calibration technique (AMA, 1951). 


\section{CHAPTER IV}

\section{RESULTS}

The purpose of this study was to establish normative data for speech stimuli utilizing the Radioear B-72 bone oscizlator. This investigation, which had a twofold purpose, attempted to: 1) establish a normal intensity level for the speech reception threshold by bone conduction; and 2) obtain a performance intensity function for bone conducted speech discrimination. The data indicated that the bone conduction speech reception threshold was definable within a small variance, and bone conducted speech discrimination results revealed a linear function that approached saturation at the limits of the audiometer.

The mean speech reception threshold (SRT) by bone conduction for the twenty-six adult subjects was $45.77 \mathrm{~dB}$ HL with a standard deviation of 3.06 . These data were normally distributed with a mode and median of $45 \mathrm{~dB} H \mathrm{HL}$ and all responses fell within two standard deviations of the mean.

When the experimental data for pure tone bone conducted thresholds were compared with the bone conducted pure tone standards used to calibrate the Portland state University (PSU) clinical audiometers, a noticeable discrepancy was 
observed (Tables II \& III). The experimental calibration values which were generally lower (except at $250 \mathrm{~Hz}$ ) than the PSU standards, may be the result of increased oscillator application force. The PSU pure tone bone conduction calibration values for the Radioear B-72, were established utilizing the Radioear P-3333 headband on a large clinical population, while all experimental data was collected only after the headband tension had been increased to the 550 grams ( \pm 50 grams) application force. Although the effect of application force on the $B-72$ bone oscillator has not been investigated, studebaker (1967) demonstrated that an increase in application force generally lowers bone conduction thresholds across all frequencies for the B-70A bone vibrator. Thus, it may be that strict adherence to the American National Standards Institute's (ANSI 1972) recommended application force $(550 \mathrm{grams})$ affected the bone conducted SRT results in the direction of lowering the mean threshold value.

It should also be noted that studebaker (1967), who found a wide variance in bone conduction scores, emphasized the need to use the median value as a measure of central tendency for bone conduction calibration. The median pure tone values for this study did not vary more than $\pm 2 \mathrm{~dB}$ for any frequency from the mean pure tone values. However, since the Radioear B-72 bone oscillator has a manufacturer's tolerance of $\pm 3 \mathrm{~dB}$ (Radioear, 1974), the median values were 


\section{TABLE II}

PORTLAND STATE UNIVERSITY CALIBRATION VALUES OBTAINED UTILIZING A RADIOEAR B-72 BONE OSCILLATOR AND RADIOEAR HEADBAND (P-3333).

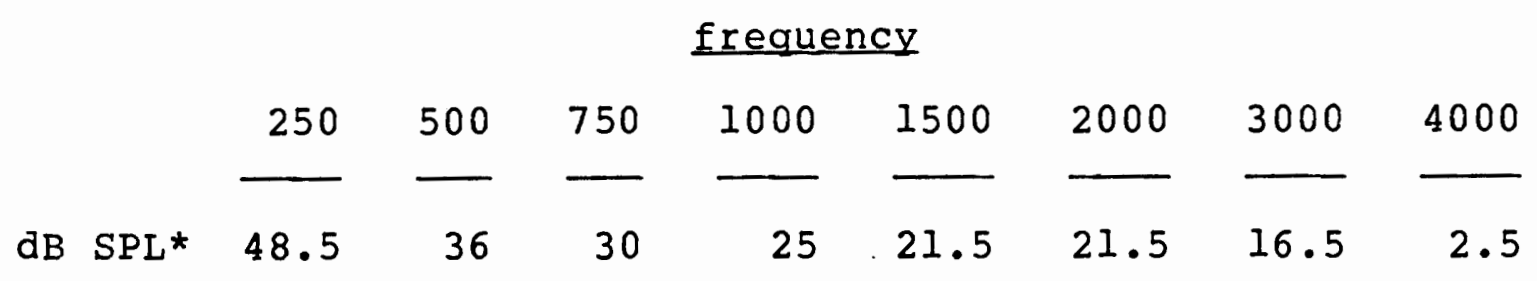

TABLE III

MEAN BONE CONDUCTION THRESHOLD VALUES ESTABLISHED BY THE EXPERIMENTAL POPULATION AFTER THE HEADBAND TENSION HAD BEEN INCREASED TO 550 GRAMS ( \pm 50 GRAMS) APPLICATION FORCE

\section{Erequency}

$\begin{array}{cccccccc}250 & 500 & 750 & 1000 & 1500 & 2000 & 3000 & 4000 \\ 50 & 31.5 & 28.5 & 20 & 18 & 19 & 14 & -0.5\end{array}$

*All calibration data determined utilizing a Bruel and Kjaer (Model 2203) artificial mastoid. 
not considered to be significantly different from the mean values.

Further evidence that the headband tension may have lowered the experimental bone conduction values may be seen by comparing the average pure tone thresholds (APT) by air and bone for the experimental population (see Table IV). The APT by air conduction was $-1.48 \mathrm{~dB} \mathrm{HL}$ and, by contrast, the bone conducted APT, which should be approximately equal to the air conduction value, was $-4.94 \mathrm{~dB}$ HL. This discrepancy between the air and bone APT appears to suggest that application force represented an intervening variable which acted to lower the mean group SRT by bone conduction. The mean SRT by air conduction was $-1.73 \mathrm{~dB}$ HL with a bimodal distribution where $0 \mathrm{~dB}$ and $-5 \mathrm{~dB} H L$ shared an equal number of responses. Thus, the air conducted APT, (-1.48 dB HL), demonstrated good agreement with the air conducted SRT. In addition, these data suggest that the experimental subjects had slightly better hearing sensitivity than audiometric zero.

The values for speech intelligibility presented in Table $V$ represent a linear function between speech discrimination scores and increased sensation level. With the exception of $20 \mathrm{~dB} S \mathrm{~S}$, the variance of speech discrimination scores observed at each sensation level was statistically significant (alpha $=0.05$ ) when compared to adjacent sensation levels within a $5 \mathrm{~dB}$ range utilizing the 
TABLE IV

AIR AND BONE CONDUCTION MEAN $(\bar{X})$ AND STANDARD DEVIATION (S.D.) VALUES FOR THE AVERAGE PURE TONE THRESHOLD (APT) AND SPEECH RECEPTION THRESHOLD (SRT) FOR HEARING LEVEL (HL)

Air Conduction APT

SRT

$-1.48 \mathrm{~dB} H L-1.73 \mathrm{~dB} H L$

3.11

3.73

3.11

Bone conduction

APT $\quad$ SRT

$\overline{\mathrm{x}}$

S.D.

4.34

3.06

* This value is significantly larger because it represents an uncalibrated presentation mode in most clinical audiometers. That is, when appropriately calibrated, this value would approximate $\mathrm{O} \mathrm{dB} \mathrm{HL}$. 


\section{TABLE V}

THE MEAN $(\bar{X})$ AND STANDARD DEVIATION (S.D.) VALUES FOR THE WORD DISCRIMINATION SCORES (WDS) AS A FUNCTION OF INCREASED SENSATION LEVELS AND AT MAXIMUM OUTPUT LEVELS FOR THE CLINICAL AUDIOMETER

\begin{tabular}{|c|c|c|c|c|}
\hline \multirow{3}{*}{$\begin{array}{l}\text { Sensation } \\
\text { Level (SL) }\end{array}$} & \multicolumn{2}{|c|}{$\begin{array}{l}\text { Number of } \\
\text { Words Correct }\end{array}$} & \multicolumn{2}{|c|}{$\begin{array}{l}\text { Percentage of } \\
\text { Words Correct }\end{array}$} \\
\hline & \multicolumn{2}{|c|}{ WDS } & \multicolumn{2}{|c|}{ WDS } \\
\hline & $\bar{x}$ & S.D. & $\bar{x}$ & S.D. \\
\hline 0 & 6.19 & 5.42 & 12.48 & 10.88 \\
\hline 5 & 15.12 & 6.17 & 30.28 & 12.28 \\
\hline 10 & 25.77 & 6.78 & 51.68 & 13.68 \\
\hline 15 & 37.12 & 5.00 & 74.28 & $10.0 \%$ \\
\hline 20 & 42.46 & 4.82 & 858 & $9.6 \%$ \\
\hline 25 & 43.88 & 2.78 & $87.8 \%$ & $5.6 \%$ \\
\hline 30 & 47.19 & 2.06 & 94.48 & $4.1 \%$ \\
\hline $\begin{array}{l}\text { Upper Limits } \\
\text { Hearing } \\
\text { Level (HL) }\end{array}$ & $\overline{\mathrm{x}}$ & S.D. & $\bar{x}$ & S.D. \\
\hline 90 & 49.08 & 1.38 & 98.28 & $2.8 \%$ \\
\hline 95 & 49.00 & 1.06 & 988 & 2.18 \\
\hline 100 & 49.50 & .76 & 998 & $1.5 \%$ \\
\hline
\end{tabular}


paired t statistic (Hewlett-Packard, 1975). Since the distribution of scores at $20 \mathrm{~dB}$ SL was widely scattered, speech discrimination testing at this sensation level could not be recommended clinically.

The slope of the line (Figure 18) from 0 SL to 15 SL was $2 / d B(4 \% / d B)$, whereas the remainder of this function through $30 \mathrm{SL}$ was characterized by a more gradual slope of $.6 / \mathrm{dB}(1.28 / \mathrm{dB})$. The configuration of this articulation curve from 0 SL to 30 SL represents a linear function with a straight-line least squares coefficient of $1.4 / \mathrm{dB}$ $(2.8 \% / d B)$.

The standard deviations for the bone conducted performance intensity function (Table V) ranged from 6.8 $(13.68)$ to $2.06(4.18)$, being largest on the leg of the articulation curve. Although 0 SL and 5 SL did not follow a projected pattern, the standard deviations from 10 SL through 30 SL demonstrated a trend of decreasing variance. When employing the $E$ test of variance between two populations, the variance between 0 SL and 30 SL was significant at the 0.01 level of confidence, indicating a significant reduction in the standard deviations as a function of increased intensity.

speech intelligibility at the maximum bone conducted output levels for a standard clinical audiometer is also presented in Table $V$. A comparison between the $95 \mathrm{~dB} \mathrm{HL}$ and the $100 \mathrm{~dB} \mathrm{HL}$ setting by the paired $\underline{t}$ statistic revealed 


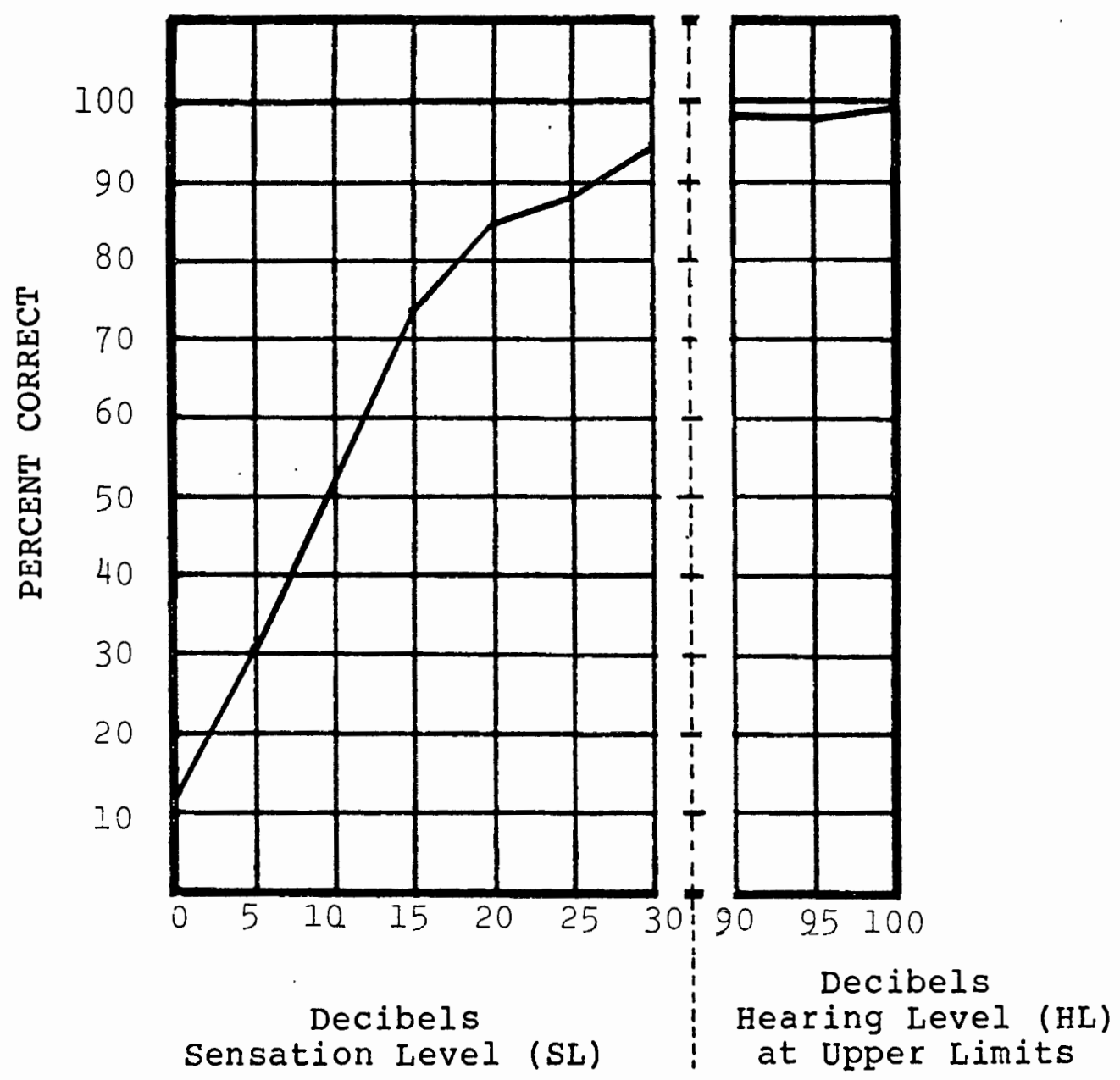

Figure 18. The mean word discrimination scores (WDS) by bone conduction for both the SL and HL values established with the research population. 
a significant difference (alpha $=.05)$. However, no significant difference of population variance was found between the $90 \mathrm{~dB} \mathrm{HL}$ and $100 \mathrm{~dB} \mathrm{HL}$ setting. The standard deviations continued the trend set by the normal articulation curve and decreased as a function of increased intensity.

Illustrated graphically, Figure 18, the slope of this speech discrimination function for 90,95 , and $100 \mathrm{~dB} H \mathrm{HL}$ was .04/dB; essentially, a straight-line function for clinical purposes. Therefore, at the limits of the audiometer for bone conducted speech (100 dB HL) there appears to be no evidence of rollover in discrimination performance. In fact, this study found a slight increase in speech discrimination results at the maximum output levels. 
CHAPTER V

\section{DISCUSSION AND SUMMARY}

This study investigated the audiometer dial setting (HL) for the normal speech reception threshold (SRT) by bone conduction, and obtained a performance intensity function for bone conducted speech discrimination. Although the Iiterature is replete with HL values for the normal bone conduction SRT, none of these studies utilized a bone vibrator which satisfied current standards recommended by the American National Standards Institute (ANSI S3.13-1972). By contrast, studies involving normal speech discrimination results by bone conduction are scarce, and again, these researchers employed apparatus that did not follow current ANSI guidelines. This investigation utilized a bone oscillator that conforms to the ANSI (S3.13-1972) recommendations and, further, the recommended application force of 550 grams was strictly monitored for all subjects.

Many modern researchers have agreed that the normal HL setting for the bone conducted SRT should be approximately $40 \mathrm{~dB}$ HL (Merrell, et al., 1973; Stockdell, 1974; Valente and Stark, 1977). However, these investigators employed the Radioear B-70A bone vibrator which, when compared to the current ANSI recommended bone oscillators, has a large 
contact surface area (approximately $3.90 \mathrm{~cm} 2$ ). At present, there are three popular bone vibrators which satisfy the ANSI requirement of $1.75 \mathrm{~cm}^{2}$ of contact surface area, the Radioear $B-71, B-72$ and the oticon $A-20$. Further, with the exception of Scrinivasan (1974), few, if any, investigators have strictly monitored the ANSI recommended vibrator application force.

Utilizing the B-72 bone vibrator and the ANSI recommended 550 grams of application force, this investigation found that the mean speech reception threshold (SRT) by bone conduction was $45.77 \mathrm{~dB} H L$. However, since the mean SRT by air conduction was $-1.73 \mathrm{~dB}$ HL and the "O" value for air conduction is well established, it appears that the sample for this study possessed hearing sensitivity slightly better than normal. Therefore, as determined by this study, normal SRT by bone conduction utlizing a B-72 bone oscillator was found to be $47.5 \mathrm{~dB} \mathrm{HL}(45.77+1.73)$.

Much of the research concerning bone conduction speech discrimination test results involved the interpretation of a word discrimination score (WDS) at the patient's most comfortable listening level (MCL) (Tato and Alfaro, 1949; Robinson and Kasden, 1970 and 1977). The prospect of administering word discrimination tests by bone conduction at sensation levels below MCL has received only scant attention in the literature (Hahlbrock, 1962). This seems unfortunate since knowledge of normative speech discrimination 
data as a function of intensity would allow clinicians to make reliable comparisons at reduced sensation levels when MCL is unobtainable due to the output limitation of standard audiometers.

This investigation developed a speech discrimination curve by bone conduction utilizing standard clinical equipment (Figure 18). Goetzinger and Proud's (1955) suggestion that a 90-100\% WDS was obtainable for normal hearing subjects at $25 \mathrm{~dB}$ SL agreed closely with the findings of this investigation. As illustrated in Figure 18, this study found that a $90 \%$ wDS could be achieved at $27 \mathrm{~dB}$ SL. Interestingly, Goetzinger and Proud recommended a monitored, live-voice presentation anò the present research utilized a tape recorded speech signal which is generally regarded as more difficult and may account for the slight discrepancy in SL values.

When MCL is not available to the clinician due to the severity of the hearing loss and the output limits of the audiometer, the performance intensity function (Figure 18) for bone conduction appears to provide an array of presentation levels (or SL's) that could substitute for the MCL value. However, the alarmingly high standard deviations $(13.6-9.6 \%)$ for each sensation level from 0 through $20 \mathrm{~dB}$ SL contraindicates the utilization of a presentation level within this range for establishing a reliable wDS (Table V). The $25 \mathrm{~dB}$ SL presentation level 
yielded a distribution that was significantly more homogeneous with a reduced standard deviation (5.68) and, therefore, represented the lowest presentation level which did not compromise the reliability of bone conducted speech testing.

A comparison between the present bone conducted speech discrimination values and two air conduction word discrimination score (WDS) investigations is presented in Table VI. While these three studies all reveal a similar slope (Figure 19), they demonstrate markedly disparate speech discrimination scores as a function of their respective experimental sensation levels. These discrepancies can be accounted for in part by the gross procedural differences in the measurement of SRT for the two air conduction investigations. The Tillman and Carhart (1966) research, which found a mean SRT value of $21.9 \mathrm{~dB}$ SPL, utilized taped test materials and a closed set of 36 spondiac words. The Beattie, et al. (1977) study used a monitored live voice presentation from a closed set of only 18 spondees and obtained a mean SRT value of II.2 dB SPL. It is this author's belief that these two investigations sampled the same population, but due to differences in methodology a procedurally specific SRT was observed in each study. That is, since the SRT provided the zero-dB sensation level from which all subsequent speech discrimination results were plotted, this initial disparity was perpetuated throughout 
TABLE VI

SOUND PRESSURE LEVEL (SPL), MEAN $(\bar{X})$, AND STANDARD DEVIATIONS (SD) OF DISCRIMINATION PERCENTAGE SCORES OBTAINED WITH N.U. AUDITORY TEST NO. 6 BY BONE CONDUCTION AND COMPARISON VALUES BY AIR CONDUCTION

\begin{tabular}{|c|c|c|c|}
\hline \multirow[b]{2}{*}{$\begin{array}{c}\text { Sensation } \\
\text { Level }\end{array}$} & BONE CONDUCTION & AIR CONDUCTION & AIR CONDUCTION \\
\hline & $\begin{array}{r}\text { Present } \\
\text { SPL } \quad \text { Study } \\
\end{array}$ & $\begin{array}{c}\text { Tillman } \\
\text { SPL } \\
\begin{array}{l}\mathrm{x} \\
\text { Carhart } \\
\text { S.D. }\end{array} \\
\end{array}$ & $\begin{array}{l}\text { Beattie, et al. } \\
\text { SPL \& } \quad \text { S.D. }\end{array}$ \\
\hline-4 & & $18 \quad 8.3$ & \\
\hline 0 & $37.5 \quad 12.4$ & $22 \quad 29$ & 11. \\
\hline 4 & & & 15. $\quad 3.4$ \\
\hline 5 & $43.5 \quad 30.2$ & & \\
\hline 8 & & $\begin{array}{lll}30 & 72.7 & 11.6 \\
\end{array}$ & 19. 12.2 \\
\hline 10 & $\begin{array}{lll}47.5 & 51.6 & 13.6\end{array}$ & & \\
\hline 12 & & & 23. 28.4 \\
\hline 15 & $\begin{array}{lll}53.5 & 74.2 & 10.0\end{array}$ & & \\
\hline 16 & & $38 \quad 91.2$ & 27. $46.9 \quad 11.1$ \\
\hline 20 & $57.5 \quad 85.0$ & & 31. 64.6 \\
\hline 24 & & $46 \quad 97.0$ & 35. $80.2 \quad 5.7$ \\
\hline 25 & $63.5 \quad 87.8$ & & \\
\hline 28 & & & 39. 87.2 \\
\hline 30 & $67.5 \quad 94.4$ & & \\
\hline 32 & & $54 \quad 99.2$ & 43. 94.7 \\
\hline
\end{tabular}


A Tillman and Carhart, 1966.

- Beattie, et al., 1977.

- Lundberg, 1981.

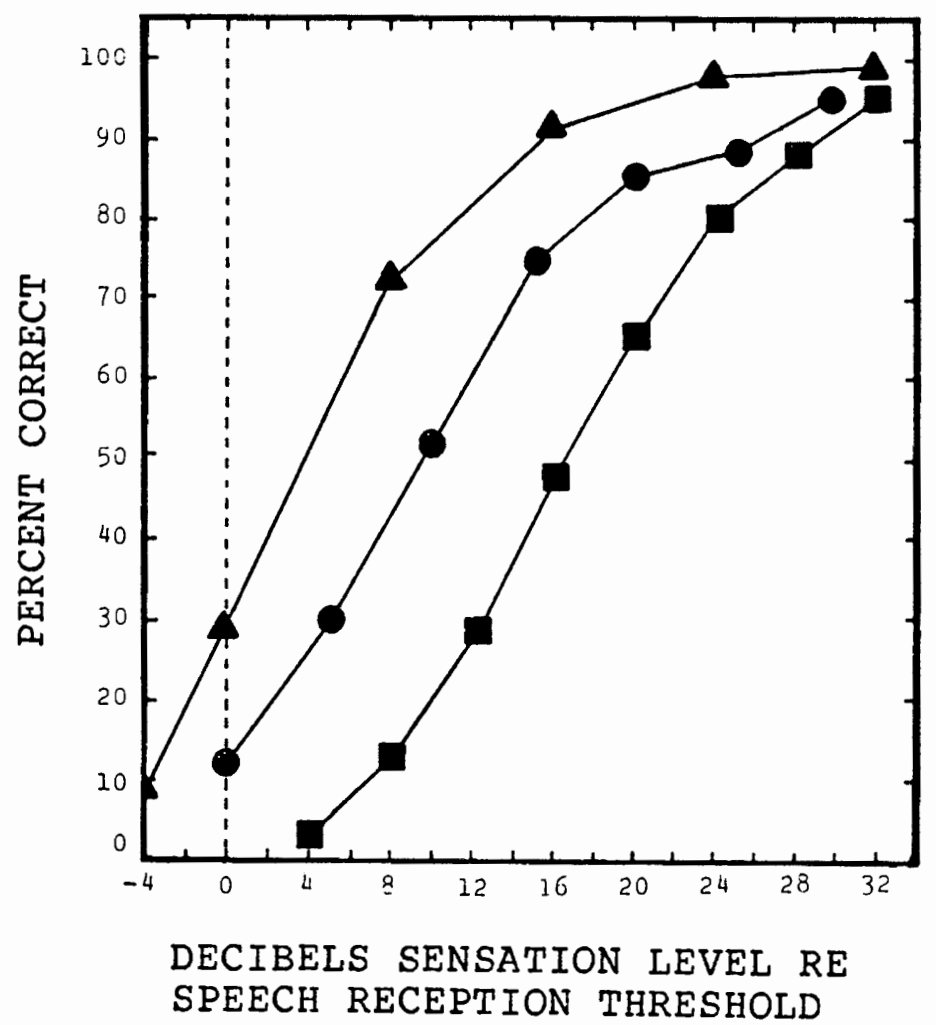

Eigure 12. A comparison between air and bone conducted speech discrimination scores as a function of sensation level. 
the entire curve for all three investigations (Figure 19). Further support for this analysis is provided by plotting the two air conduction investigation results on the same sound pressure level (SPL) graph. Figure 20 illustrates the very close agreement between these two speech discrimination functions when the $0 \mathrm{~dB} S L$ (SRT) bias is eliminated.

Equating the Tillman and Carhart (1966) and Beattie, et al. (1977) data with the present bone conduction articulation curve (Figure 20) reveals a high correlation $(\underline{r}=.98$ and $\underline{r}=1.0$ respectively). The approximately $20 \mathrm{~dB}$ SPL disparity which separates the two air conduction articulation function curves from the bone conduction articulation function curve is best accounted for by the artifact introduced when making SPL measurements utilizing an artificial mastoid.

Recently, Barry and Geddis (1978) investigated bone conducted speech discrimination at the maximum output levels of the audiometer utilizing a $\mathrm{B}-70 \mathrm{~A}$ bone oscillator in tandom with an in-line amplifier for the speech circuit. Their results did not correlate well with the present investigation at higher presentation levels. Essentially, the discrepancy between their findings and this study's centered around an appropriate intensity for zero-dB HL (SRT) for bone conduction. Barry and Geddis maintained that the zero-dB HL should be $64.7 \mathrm{~dB}$ SPL while the present study found the 
- Tillman and Carhart, 1966.

- Beattie, et al., 1977.

- Lundberg, 1981.

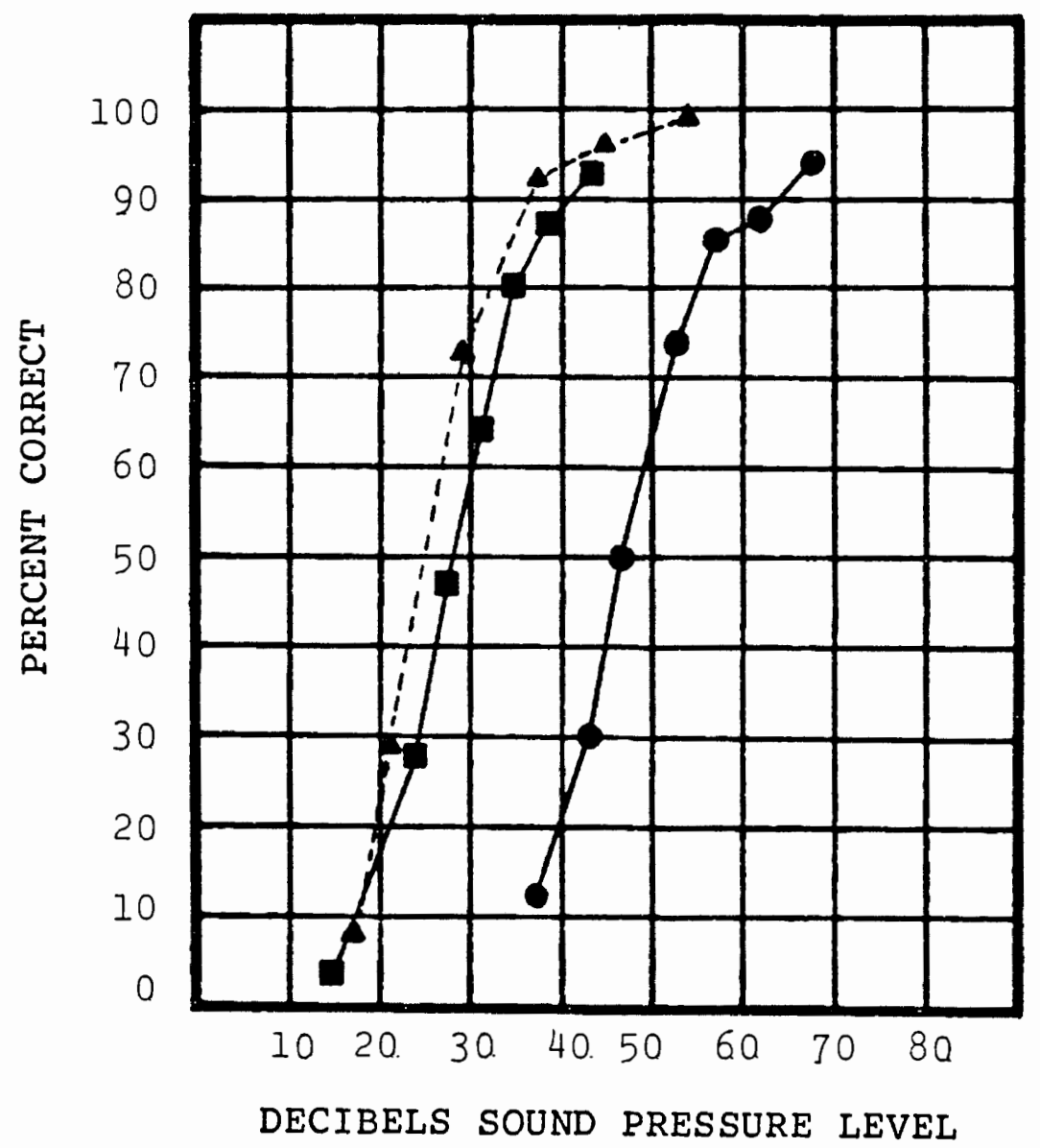

Eigure 20. A comparison between air and bone conducted speech discrimination scores as a function of sound pressure level. 
zero-dB HL value to be $39.5 \mathrm{~dB}$ SPL, or approximately 25 $d B$ less output. That is, their in-line amplifier provided a boost of approximately $25 \mathrm{~dB}$ SPL over what would normally be expected utilizing the conventional mode for bone conducted speech. Consequently, it is not surprising to note that Berry and Geddis found a 958 wDS at $20 \mathrm{~dB}$ SL, or $84.7 \mathrm{~dB}$ sound pressure level (SPL), and noticed a distortion component developing at $50 \mathrm{~dB}$ SL $(114.7 \mathrm{~dB}$ SPL). By contrast, this present study did not demonstrate a 958 WDS until $30 \mathrm{~dB}$ SL (68.5 $\mathrm{dB}$ SPL) and no distortion was observed at the maximum output of our conventional audiometer's speech mode 52.5 dB SL $(90.9 \mathrm{~dB}$ SPL). Thus, $114.7 \mathrm{~dB}$ SPL of bone conducted speech may indeed produce a distortional element as Barry and Geddis reported, but at the limits of most standard audiometers (90.9 dB SPL, or $100 \mathrm{~dB} H L)$ no roll-over for speech discrimination was observed by either Barry and Geddis or the present investigator.

\section{Conclusion}

This study established an HL value for the normal speech reception threshold (SRT) and developed a normal speech discrimination curve as a function of increased intensity for the Radioear B-72 bone oscillator. The normal SRT by bone conduction was determined to be $47.5 \mathrm{~dB} H \mathrm{H}$ which corresponds to an objective calibration value, utilizing a $B \& R$ artificial mastoid and a $1000 \mathrm{~Hz}$ tone, of $39.5 \mathrm{~dB}$ SPL. 
Although never stated directly, it was reasoned that the bone conduction articulation function data would have predictive value in instances where sensation levels (SL) lower than the most comfortable listening level (MCL) were employed. That is, since most clinical audiometers typically have a maximum speech output of $100 \mathrm{~dB} H L(52.5 \mathrm{~dB}$ SL) by bone conduction and the optimum level for bone conducted speech discrimination appears to be $25 \mathrm{~dB}$ SL, it was hoped that the data would allow normal hearing inferences based upon presentation levels substantially below the optimum level. However, the analysis of the findings at low sensation levels ( 0 - $20 \mathrm{~dB}$ SL) revealed large variances thus precluding their use for establishing normal discrimination ability when reduced SL's are used.

\section{Implications For Further Research}

The results of this research indicate several areas for future study. An investigation which compared the SRT's of normal hearing children to those with established conductive components utilizing the Radioear B-72 bone oscillator would provide valuable corroborative information in light of the present findings. Also, since the present study has determined the performance intensity function for bone conducted speech discrimination results for a normal adult population, the value of a similar study administered to a sample of otosclerotic, hearing impaired subjects could 
possibly demonstrate a high correlation between these two different populations and, thereby, reveal highly predictive information for candidates of middle ear surgery.

A major, procedural issue involved in the present bone conduction study was oscillator application force. In this research, the application force was held constant (550 grams), however, to maintain the required pressure for each subject the headband (Radioear P-3333) was adjusted by utilizing additional padding in order to accommodate various head sizes. Since a wide variance in headband tension ( \pm 200 grams) was observed prior to the headband adjustment, the need for research which would examine the effects of application force on bone conducted speech results seems paramount.

Finally, bone conducted speech testing with the use of contralateral masking provides a rather unique listening task, and one where the possibility of a release from making may occur. This phenomenon, also known as making level differences (MLD) occurs when both ears receive stimulation as in the case of bone conduction listening. The MLD has not been explored with regard to bone conducted speech signals, and, at present, any advantage gained under this listening condition can only be speculated. 
REFERENCES

American Medical Association, "Specifications of the Council on Physical Medicine and Rehabilitation of the American Medical Association." JAMA, 146:225-7, 1951.

American National standards Institute, "Specification for an Artificial Head-Bone for Calibration of Audiometer bone Vibrators." ANSI, S3.13-1972, New York: American National Standards Institute, 1972.

Audibel Wholesale, Inc., Personal Communication, 1980.

Barry, S. J. and Geddis, S., "Physical and Physiological Constraints on the Use of Bone Conduction speech Audiometry." JSHD, 43:220-6, 1978.

Barry, S., Maico Corporation, Personal Communication, 1980.

Beattie, R. C., Edgerton, B. J., and Svihovec, D. V., "A Comparison of the Auditec of St. Louis Cassette Recordings of $\mathrm{NU}-6$ and CID $\mathrm{W}-22$ on a Normal-Hearing Population." JSHD, 42:60-4, 1977.

Bekesy, G. V. "The Structure of the Middle Ear and the Hearing of One's Own Voice by Bone Conduction." JASA, $21: 217-32$, 1949 .

durch Knochenleitung." Annalen Der Physik, 13:111-36. 1932 .

Berger, K. W., "History and Development of Hearing Aids." In Amplification for the Hearing-Impaired, Pollack, M. C. (Ed.), New York: Grune and Stratton, 1975 .

Bruel and Rjaer Artificial Mastoid 4930 Instruction Manual, 1974 .

Carhart, R. C., "Clinical Application of Bone Conduction Audiometry." Arch. Otolaryn., 51:798-808, 1950 .

Carhart, R. C. and Hayes, C., "The Clinical Reliability of Bone Conduction Audiometry." Laㅗ브으옫ㅇ을, 59:1084-1101, 1949 . 
Carlisle, R. W. and Pearson, H. A., "A Strain-Gauge Type Artificial Mastoid." JASA, 23:300-2, 1951.

Committee on Methods of Testing Bone Conduction, "Hearing by Bone Conduction." Trans. Am, Otol. Soc., 26:1-185, 1936.

Corliss, E. L. R, and Koidan, W., "Mechanical Impedance of the Forehead and Mastoid." JASA, 27:1164-72, 1955.

Corvec Medical Equipment Co., Personal Communication, 1980.

Dirks, D. D., "Bone-Conduction Testing." In Handbook of Clinical Audiology, Katz, J. (Ed.), Baltimore: Williams and Wilkins Co., 1978.

Dirks, D. D. and Kamm, C., "Bone-Vibrator Measurements: Physical Characteristics and Behavioral Thresholds." JSHR, 18:242-60, 1975 .

Fowler, E. P. (Sr.) and Fowler, E. P. (Jr.), "Normal Hearing by Bone Conduction as measured with an Audiometer." Trans. Am, Otol. Soc., 26:33-8, 1936.

Goetzinger, C. P. and Proud, G. O., "Speech Audiometry by Bone Conduction." Arch. Otolaryn., 62:632-5, 1955.

Grossman, F. M. and Molloy, C. T., "Physical Characteristics of Some Bone oscillators used with Commercially

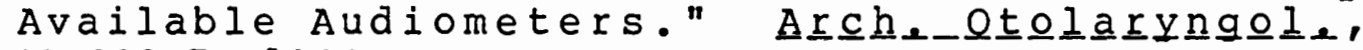
$40: 282-7$, 1944 .

Hahlbrock, K. H., "Bone Conduction Speech Audiometry." International Audiology, 1:186-8, 1962 .

Hawley, M. S., "An Artificial Mastoid for Audiphone Measurements." Bell Lab. Rec,, 18:73-5, 1939.

Hewlett-Packard, HP-25 Applications Programs. Corvallis: Hewlett-Packard Co., 1975.

Hicks, A., "The Use of the Goetzinger Technique in Clinical

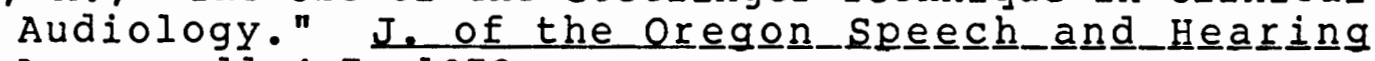
Assoc, $11: 4-7,1972$.

Hood, J. D., "Bone Conduction: A Review of the present Position with Especial Reference to the Contributions of Dr. Georg Von Bekesy." JAㅗㄹㅡ, $34: 1325-32$, 1962 .

Jones, I. H. and Knudsen, V. O., "Audiometry and the Prescribing of Hearing Aids." Laㅡ믐으으으르, $46: 523-36,1936$. 
Kasden, S. D. and Robinson, M., "Bone Conduction Speech Discrimination in Different Pathologies." IER, $13: 268-70$, 1973 .

Klodd, D. A. and Edgerton, B. J., "Occlusion Effect: Bone Conduction Speech Audiometry Using Forehead and Mastoid Placement." Audiol. 16:522-9, 1977.

Knudsen, V. O. and Jones, I. H., "Bone Conduction." Arch otolaryngol., 13:489-505, 1931 .

\section{$34: 671-86,1924$.}

Lierle, D. M. and Reger, S. N. "Correlations Between Bone and Air Conduction Acuity Measurements Over Wide Frequency Ranges in Different Type of Hearing Impairments." Laryngoscope, 56:187-224, 1946.

Lowy, K., "Cancellation of the Electrical Cochlear Response with Air-and Bone-Conducted Sound." JASA, 13:156-8, 1942 .

Lybarger, S. F., "Interim Bone Conduction Thresholds for Audiometry." JSHR, 9:483-7, 1966.

Mendenhall, W., Introduction to Probability and statistics. North Scltuate: Duxbury Press, 1975.

Merrell, H. B., Wolfe, D. L. and McLemore, D. C., "Air and Bone Conducted Speech Reception Thresholds." Laryngoscope, 83:1929-39, 1973 .

Miller, A. L., "The Use of Masked Bone-Conducted Speech as an Aid in the Detection of Feigned Unilateral Hearing Losses." JSHD, 29:333-5, 1964.

Miner, R. C. "A Bone-Conduction Receiver for the Audiphone." Be11 Lab. Rece, 13:364-8, 1935.

Pohlman, A. G. and Kranz, F. W., "Monaural Tests on Bone Acuity Under Various Conditions, with some General

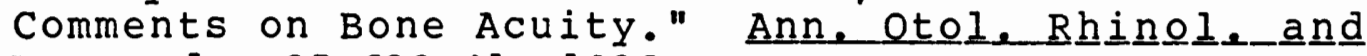
Laryngole, 35:632-41, 1926.

"A New Auditory Test Apparatus." Proc. Soc. Exp. Biol. and Med, 20:392, 1923. 
Pohlman, A. G. and Kranz, F. W., "The Problem of Middle Ear Mechancis. Chapter III. Binaural Acuity for Air and Bone Transmitted Sound Under Varying Conditions in the External Auditory Canal." Ann. Otol. Rhingol. and Laryngole, $34: 1224-42,1925$.

Pohlman, A. G., "Apparatus for the Quantitative Testing of Air and Bone Transmitted Speech." Proc. of the Soc. for Exper. B10. and Med, 26:355-6, 1929 .

"The Possibilities in the Quantitative Correlation Between Air and Bone Transmitted Speech." Laryngoscope, 41:157-65, 1931 .

Radioear Corporation, "B-71, B-72 Vibrators Preliminary." Radioear Corp. Eng. Bull., 1974.

Roach, R. E. and Carhart, R. C., "A Clinical Method for Calibrating the Bone Conduction Audiometer." Arch. otolaryngole, 63:270-9, 1956 .

Robinson, M. and Kasden, S. D., "Bone Conduction Speech Audiometry." Annals of otology, 79:818-24, 1970 .

"Bone Conduction Speech Discrimination." Arch. Otolaryngole, $103: 238-40,1977$.

Sanders, J. W. and Olsen, W. O., "An Evaluation of a New Artificial Mastoid as an Instrument for the Calibration of Audiometer Bone-Conduction systems ." JSHD, $29: 247-63$, 1964 .

Scrinivasan, K. P., "Bone-Conducted speech Reception Threshold." Scand. Audiol., 3:145-8, 1974.

Senturia, B. H. and Thea, A. R., "Bone Conduction in Audiometry. Literature Review and Report of Preliminary Observations." Laryngoscope, 52:675-87, 1942.

Steinberg, J. C., "Effects of Distortion Upon the Recognition of Speech Sounds." JASA, 1:127-37, 1929.

Stockdell, K. G., "Speech by Bone Conduction in Diagnostic Audiometry." Audecibel, 23:100-9, 1974 .

Studebaker, G. A., "The Standarization of Bone-Conduction Thresholds." Laryngoscope, 77:823-35, 1967.

Tato, J. M. and Alfaro, D., "Speech Audiometry Discrimination by Bone Conduction." Proc. IVth Intle Cong. Otolaryngole, 1:78-82, 1949. 
Tillman, T. W., and Carhart, R. C., "An Expanded Test for Speech discrimination Utilizing CNC Monosyllabic Words." School of Aerospace Medicine, Brooks AFB, Texas, 1966.

Tonndorf, J., "Bone Conduction." In Foundations of Modern Audiotry Theory, Vol. I, Tobias, J. (Ed.), New York: Academic Press, 1972 .

Valente, M. K. and Stark, E. W., "Bone-Conducted speech Audiometry." JAR, 17:105-8, 1977.

Watson, N. A., "Hearing of speech by Bone Conduction." JASA, 9:99-106, 1937 .

Weiss, E., "An Air Damped Artificial Mastoid." JASA, $32: 1582-8,1960$.

Wilbur, L. A., "American National standard specification for an Artificial Head-Bone." ASHA, 16:71-73, 1974. Signals." "In Handbook of Clinical Audiology, Katz, J. (Ed.), Baltimore: Williams and Wilkins Co., 1978 .

Wilbur, L. A. and Goodhill, V., "Real Ear Versus Artificial Mastoid Methods of Calibration of Bone-Conduction Vibrations." JSHR, 10:405-16, 1967. 